TITLE:

\title{
Ultra-precision finishing of low expansion ceramics by compliant abrasive technologies: A comparative study
}

$\operatorname{AUTHOR(S):~}$

Zhu, Wu Le; Beaucamp, Anthony

\section{CITATION:}

Zhu, Wu Le ...[et al]. Ultra-precision finishing of low expansion ceramics by compliant abrasive technologies: A comparative study. Ceramics International 2019, 45(9): $11527-$ 11538

ISSUE DATE:

2019-06-15

URL:

http://hdl.handle.net/2433/240875

RIGHT:

(C) 2019. This manuscript version is made available under the CC-BY-NC-ND 4.0 license

http://creativecommons.org/licenses/by-nc-nd/4.0/.; The full-text file will be made open to the public on $15 \mathrm{June} 2021$ in accordance with publisher's 'Terms and Conditions for Self-Archiving'.; この論文は出版社版でありません。引用の際 には出版社版をご確認ご利用ください。; This is not the published version. Please cite only the published version. 


\title{
Ultra-Precision Finishing of Low Expansion Ceramics by Compliant Abrasive Technologies: a Comparative Study
}

\author{
Wu-Le Zhu ${ }^{1}$, Beaucamp Anthony ${ }^{1, *}$ \\ ${ }^{1}$ Department of Micro-Engineering, Kyoto University, Japan \\ *Corresponding author: beaucamp@me.kyoto-u.ac.jp
}

\begin{abstract}
:
Advanced ceramics have many attractive features such as high stability and wear resistance that find broad applications in various fields, e.g. optics, aerospace, etc. However, the accompanying difficult-to-machine property with complex geometry brings great challenges to the commonly used laser machining and rigid wheel based grinding in industry. To achieve optical surface quality with surface roughness below $10 \mathrm{~nm}$ Ra, three promising ultra-precision compliant machining technologies using adaptive elastic tools are presented in this paper, including bonnet polishing, compliant pitch polishing and shape adaptive grinding with fine grain size. A comparative study was conducted by machining three different low thermal expansion ceramics while continuously increasing attack angle, spindle speed and tool offset across rectangular regions. Material removal rate (MRR) and surface roughness (Ra) with respect to different process conditions are compared. With sufficient data, the processing ability using above three compliant machining technologies is summarized based on the MRR-Ra plots for different ceramics. In addition, microscopic observation and X-ray diffraction analysis are conducted to characterize differences in material behavior.
\end{abstract}

Keywords: Ultra-precision compliant machining, ceramics processing, material removal rate, surface roughness 


\section{Introduction}

Advanced structural ceramics, such as very low thermal expansion ceramics (LTEC), are finding an increasing demand in many applications, e.g. artificial joints, next-generation computer memory, biomedical devices, optical mirrors in aerospace, etc., due to their superior material properties including high thermal stability, high hardness, high wear resistance and so on $[1,2]$. However, low fracture toughness and brittleness lead to their difficult-to-machine nature. On the other hand, high surface quality is essentially needed to satisfy high functional performance in applications. Therefore, advances in ceramic machining technology are necessary for commercialization of improved technology, productivity, and increased product quality [3].

To improve the machinability in ceramics processing, numerous attempts have been tried in the last decades, such as abrasive water jet machining [4], micro electro discharge machining [5], pulsed laser ablation [6], laser milling [7], etc. However, the energy based machining approach results in low surface integrity with roughness of tens of microns and generally induces thermal stress. As comparison, tool based mechanical machining method is effective to perform accurate machining with improved surface quality. For diamond cutting or milling, due to the high hardness of ceramics, it is usually implemented with assistance from extra energy, such as laser spot heating [8], atmospheric-pressure plasma jet [9], ultrasonic vibration $[10,11]$, in order to expand the ductile removal regime and avoid fracture generation. As a result, the machinability is improved and the surface roughness could be reduced to several microns. As for grinding with diamond wheel, it is a widely used option in industry to achieve a good accuracy and surface quality. However, its problem lies in the limited degree of freedom in machining complex surfaces and high machining expenses [12]. 
Besides, the surface crack and subsurface damage can be easily generated due to the hard contact between the rigid wheel and brittle ceramics. To mitigate this problem, ultrasonic assisted grinding has been adopted for ductile grinding of ceramics, and the experiments show the material removal rate can be increased while keeping free from subsurface damage [13]. Nevertheless, the grinding process based on hard contact is still not capable of achieving ultra-precision criteria often expected by designers, especially for optical applications [14], and thus it cannot be treated as a finishing step for high quality products.

Chemical mechanical polishing is a commonly used ultra-precision finishing process, where a rotating workpiece is pressed face down onto a rotating polishing pad while polishing slurry containing loose abrasive particles flows in to remove the material [15]. In spite of nanoscale surface roughness that can be obtained, the drawback is the limitation to the planar workpiece in principle. As a computer controlled polishing method, magnetorheological finishing process is applying an electromagnetic field to pull the slurry and generate shear stress for removing the material [16]. It has many advantages like the high removal rate and nano-scale roughness that can be achieved. However, a special magnetorheological fluid is needed and the complexity of slurry system have restricted its adoption so far. Ion beam figuring technology could realize high material removal rate for surface form correction [17], yet it is not good at removing high frequency roughness in the micro-scale. Recently, there are also some new finishing processes developed for ultra-precision accuracy, e.g. ultrasonic two-axis vibration assisted polishing [18]. It has shown roughness below $5 \mathrm{~nm}$ was successfully achieved on high numerical aperture mold. Nevertheless, it would take an excessively long time for processing larger molds up-to 50 $\mathrm{mm}$ diameter by this technique. As another developed approach unlike conventional grinding, 
electrolytic in-process dressing (ELID) grinding could achieve ultra-precision finishing of structural ceramics, surface roughness below $10 \mathrm{~nm}$ has been obtained by using fine grain size of $4 \mu \mathrm{m}$ [19]. It is a cost-effective and efficient solution for ceramics processing in large scale, however, it is mainly used for the planar ceramics finishing.

As stated in [3], most industrialized countries of the world have invested heavily in the processing of new ceramic materials, for the production of lower-priced ceramics with better properties. As an innovative computer controlled compliant finishing process, bonnet polishing based on tool precession has been described in previous work at various stages of its development by Walker, Beaucamp and their colleagues $[1,14,20]$. As illustrated in Fig. 1(a), due to the utilization of elastic tool, it could achieve good compliance with flat, aspheric or even freeform shape [21]. As further developments, polishing pad could be also replaced by optical pitch and fabric sheet deposited with diamond grains, constituting two other technologies, namely compliant pitch polishing (CPP) and shape adaptive grinding (SAG), as shown in Fig. 1(b)\&(c). Unlike the conventional rigid wheel based grinding, the SAG process with fine grains could also achieve ultra-precision finishing with surface roughness less than $2 \mathrm{~nm}$ [22]. In spite of much research conducted on bonnet polishing and SAG process, there is still serious lack of comparative work in processing various attractive ceramics materials using the different methods described above.

On the other hand, some work has been published on the effect of finishing processes on the workpiece surface and subsurface from the perspective of material science. For instance, Luo et al. disclosed the material behavior after magnetorheological finishing at atomic scale based on morphology observation and X-ray diffraction analysis [23, 24]. Bismayer et al. investigated the subsurface damage in silicon wafers by grinding and lapping [25]. 
Nevertheless, a comparative study on the surface and sub-surface influence of brittle, ductile, and especially compliant finishing process, has not been revealed yet.

Therefore, this paper will focus on an experimental comparison to investigate the processing abilities of different compliant finishing methods and their processing domains for different ceramics. High magnification microscopic images and X-ray diffraction analysis will be presented to distinguish the effect of different methods on the finished surfaces. This work is expected to provide guidance for parameter selection and process optimization in ultra-precision machining of advanced ceramics.

\section{Materials and methods}

\subsection{Compliant abrasive technologies}
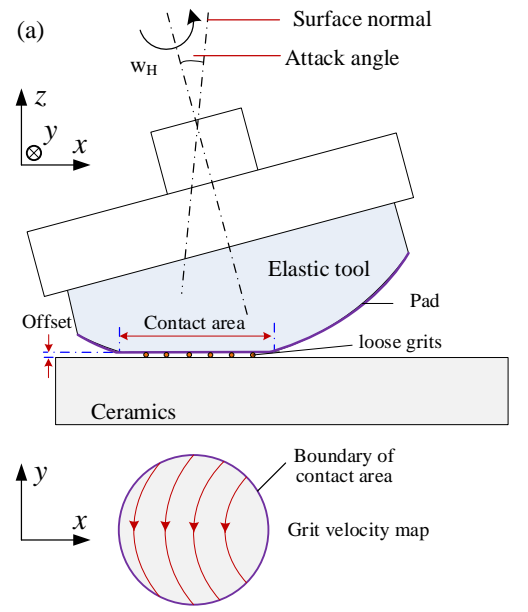
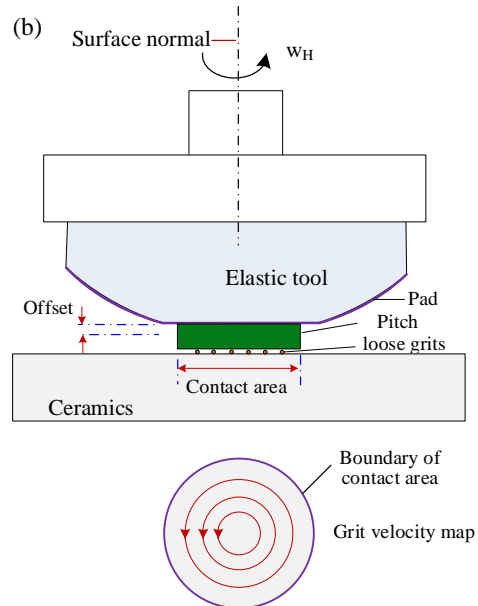
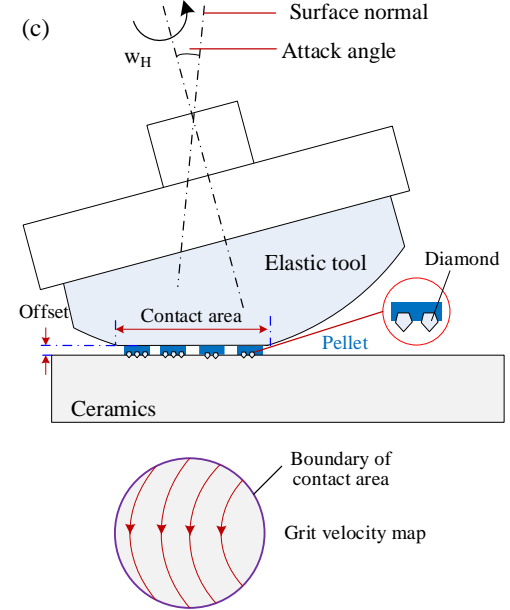

Fig. 1 Schematics of different compliant abrasive technologies, (a) bonnet polishing, (b) compliant pitch polishing, (c) shape adaptive grinding

Three types of promising compliant abrasive technologies will be investigated to study the processing performances of ceramics. As the first type, in bonnet polishing as shown in Fig. 1(a), the position and orientation (precession angle) of a spinning $\left(\mathrm{w}_{\mathrm{H}}\right)$ elastic rubber tool can be actively controlled as it traverses the ceramic surface. On the rubber tool, the pad made of polyurethane (LP66, Universal Photonics) or poromeric cloth (Uninap 13, Universal 
Photonics) is adopted to interact with the workpiece, between which the loose grits provided by cyclic slurry delivery are actively removing the materials in micro/nano-scale under pressure from the deformation of the elastic tool, e.g. rubber bonnet. Therefore, the material removal rate and surface quality are determined by the pressure in the contact region, offset value, attack angle, spinning speed, rubber/pad material, grit size/type, workpiece material, etc.

If very fine grits (e.g. size $<0.5 \mu \mathrm{m}$ ) are introduced to reach higher surface quality, the extremely small grit size might be trapped inside the pad material, probably leading to very low material removal amount. Evolved from the bonnet polishing, the compliant pitch polishing is using optical pitch shaped in circular shape to make the loose grits interact with the workpiece, as illustrated in Fig. 1(b). The pitch is relatively hard, but can be reshaped by heating, to comply with the workpiece form before polishing. In this process, the attack angle is set to be zero to keep the pitch fully in contact with the workpiece, that is the top surface of the pitch dollop attached to the elastic tool. Likewise, the material removal rate and surface quality are affected by offset value, pitch size, spinning speed, grit size/type, rubber material, workpiece material, etc. This method is expected to achieve improvement in surface quality as well as high material removal rate.

To have a significantly higher material removal, grinding is mostly employed. Nevertheless, when processing brittle ceramic materials, it could easily generate the fracture and degrade the surface quality, especially for conventional grinding based on rigid wheel. As a further evolution from the bonnet polishing, the shape adaptive grinding (SAG) process recently proposed by Beaucamp et al [22], as another compliant machining method, is capable of freeform finishing difficult materials rather than rough machining. Instead of hard 
contact, the SAG also uses an elastic tool to achieve shape compliance with the workpiece, while the material is removed at micro/nano-scale by the diamond grits that are deposited on nickel or resin pellets, as illustrated in Fig. 1(c). With fine diamond grits (e.g. size $<3 \mu \mathrm{m}$ ), optical surface with roughness below $1 \mathrm{~nm}$ can be achieved on $\mathrm{SiC}$, which shows potential to realize both high material removal and smooth surface finishing quality. The size of compliant contact area is controlled by offsetting the elastic tool against the workpiece, whereas the finishing quality is affected by the diamond grit size, offset, spinning speed, rubber material, workpiece material, etc.

It can be found that above three methods have different features in ultra-precision finishing of ceramic materials, and the process performance depends on the specific type of ceramics. Consequently, comparative study and analysis will be conducted in the following sections.

\subsection{Investigation method}
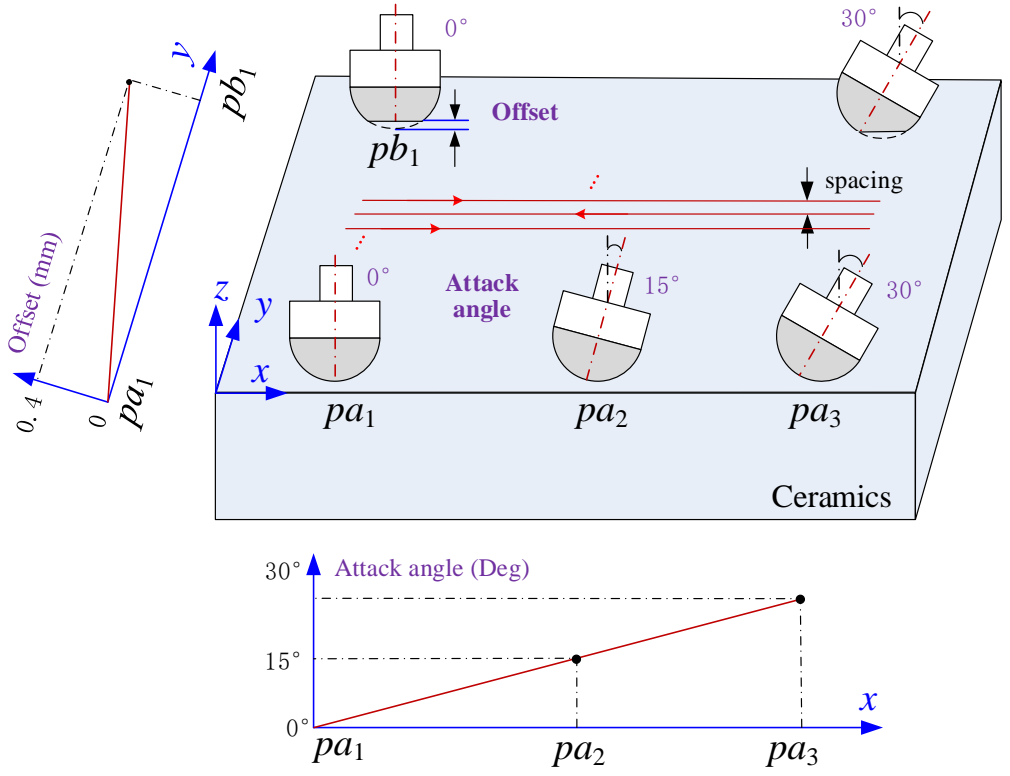

Fig. 2 Illustration of experimental method for ceramic processing 
To obtain sufficient and reliable information from each processing cycle for comparisons, a new experimental method based on continuously varying parameters is described in this section. The raster path was firstly planned on the rectangular ceramic surface, with feed motion in $x$ direction and step motion in $y$ direction. As illustrated in Fig. 2(a), along the feed direction, the attack angle is continuously varied from 0 to $30^{\circ}$, while the offset is gradually increased from $0.1 \mathrm{~mm}$ to $0.4 \mathrm{~mm}$ along the step direction. The offset map and attack angle map in the rectangular processing area are plotted in Fig. 2(b). For the compliant pitch polishing process, as the attack angle must be kept zero, the spindle speed is varying from $200 \mathrm{rpm}$ to $1600 \mathrm{rpm}$ along $x$ direction instead.

(a)

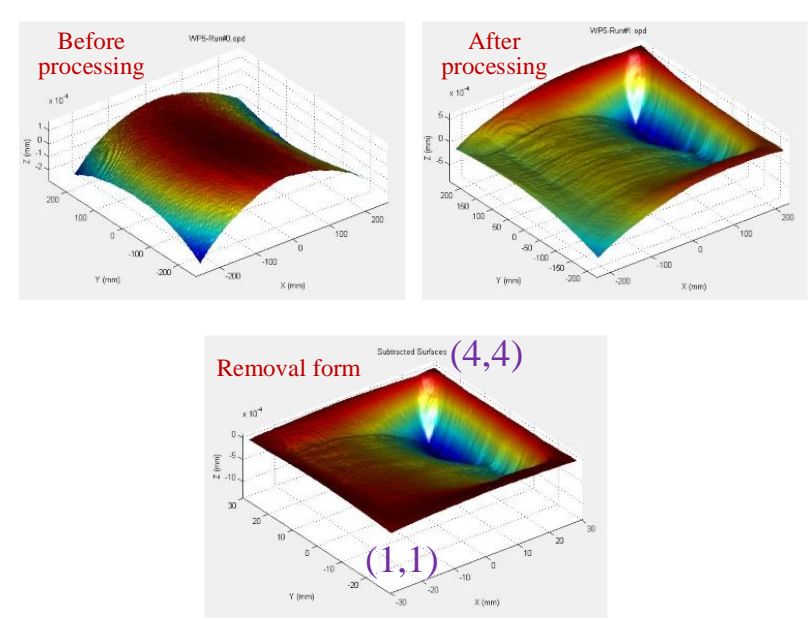

(b) Attack angle/Spindle speed

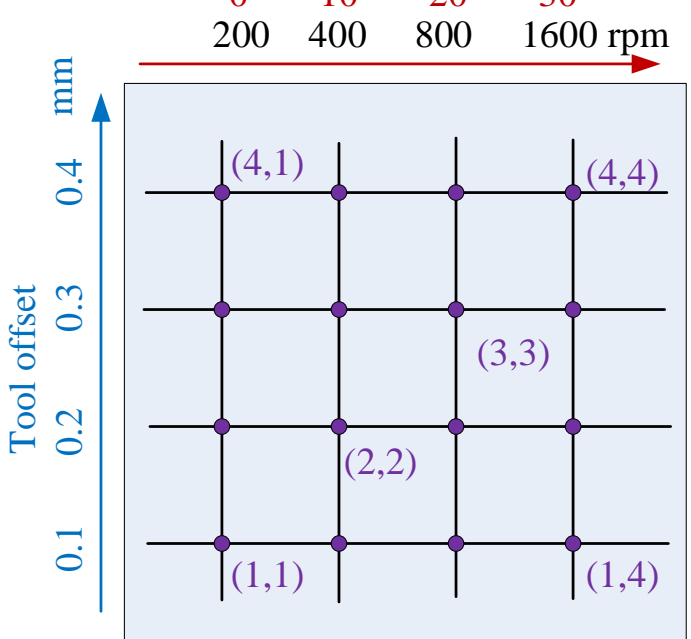

Fig. 3 (a) Form evaluation method, (b) illustration of evaluation method for each processed ceramics

To accurately evaluate the material removal profile, the surface forms before and after processing are measured using either a Fizeau interferometer (NT4100, Wkyo), or stylus based profiler (PGI, Taylor Hobson) for surface form with large depth. The removal form can be obtained by form subtraction before and after, as illustrated in Fig. 3(a). To calculate the material removal rate (MRR) under different conditions, the processed ceramics are evenly 
divided into 16 points by a mesh grid and numbered from $(1,1)$ to $(4,4)$, as shown in the top view of Fig. 3(b). The MRR at each grid point is defined by:

$$
\operatorname{MRR}(i, j)=\frac{\left[h(i, j)-h_{0}(i, j)\right] \cdot A}{t}
$$

where $h(i, j)$ and $h_{0}(i, j)$ are the form depths before and after machining at any evaluation point $(i, j)$ according to Fig. $3(\mathrm{~b}), A$ is the machining area, and $t$ is the total machining time. Each point is also measured three times by white light interferometer (NT2000, Wkyo) with $50 \times$ objective, to obtain the average value of $R_{a}$ (arithmetical mean deviation of the assessed area after removing the tilt and power) for the representation of surface roughness. Likewise, the surface roughness of corresponding evaluation point is denoted as $\mathrm{Ra}(i, j)$.

Table 1. Material properties of three ceramics

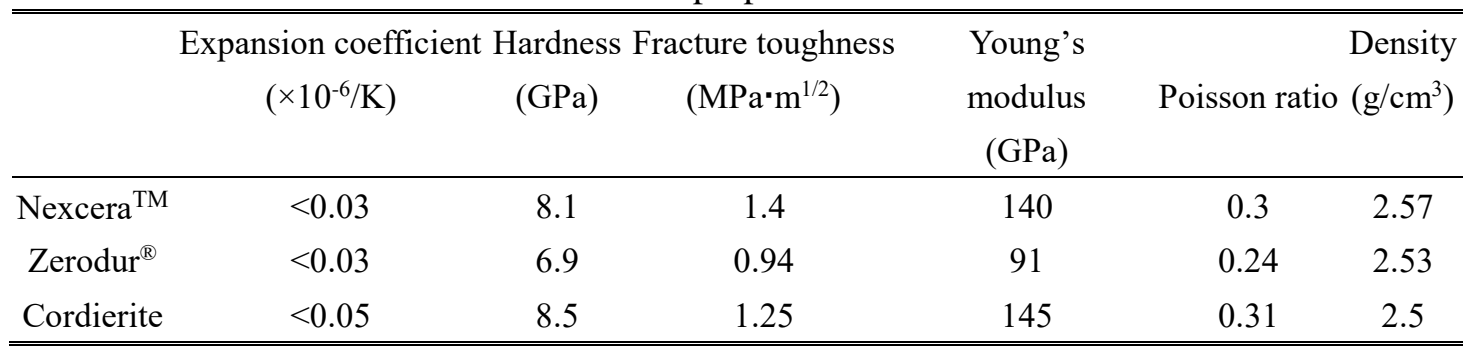

Three low thermal expansion ceramics were investigated, namely Nexcera ${ }^{\mathrm{TM}}$ (Type CD107) produced by Krosaki Japan, Zerodur ${ }^{\circledR}$ produced by Schott AG Germany, and Cordierite (Type Cordierite) manufactured by Kyocera Japan. The material properties including expansion coefficient, Vickers hardness, fracture toughness, etc., are listed in Table 1 according to the product specifications for all three low thermal expansion ceramics. Three types of compliant abrasive technologies have been applied, where the grit type and size are different, as listed in Table 2. Apart from the above described varying process conditions, all tools had a radius of $12 \mathrm{~mm}$ and rubber hardness of $60 \mathrm{~A}$. The feed speed is $300 \mathrm{~mm} / \mathrm{min}$ with 
spacing of $0.2 \mathrm{~mm}$ in $y$ direction. The slurry concentration in BP and CPP was $40 \mathrm{~g} / \mathrm{L}$. The total processing time is about $43 \mathrm{~min}$ for an area of $50 \mathrm{~mm} \times 50 \mathrm{~mm}$.

Table 2. Experimental process parameters

\begin{tabular}{|c|c|c|c|c|c|c|c|c|}
\hline \multirow[b]{3}{*}{ Grit size } & \multicolumn{3}{|c|}{ Ceramic processing methods } & \multirow{2}{*}{$\begin{array}{l}\text { Workpiece } \\
\text { Material }\end{array}$} & \multicolumn{4}{|c|}{ Conditions } \\
\hline & SAG & BP & CPP & & & & & \\
\hline & $\begin{array}{l}9 \mu \mathrm{m}, 3 \\
\mu \mathrm{m}\end{array}$ & $1.5 \mu \mathrm{m}$ & $\begin{array}{l}1.5,0.5,0.2 \\
\mu \mathrm{m}\end{array}$ & Nexcera $^{\mathrm{TM}}$ & Offset & $0.1-0.4 \mathrm{~mm}$ & $\begin{array}{l}\text { Rubber } \\
\text { hardness }\end{array}$ & $60 \mathrm{~A}$ \\
\hline Grit Mat. & Diamonc & $\mathrm{CeO}_{2}$ & $\mathrm{CeO}_{2}, \mathrm{Al}_{2} \mathrm{O}_{3}$ & Zerodur $^{\circledR}$ & Attack & $0-30^{\circ}$ & Spacing & $0.2 \mathrm{~mm}$ \\
\hline Pad Mat. & $\begin{array}{l}\text { Metal } \\
\text { fabric }\end{array}$ & $\begin{array}{l}\text { Uninap 13, } \\
\text { LP66 }\end{array}$ & $\begin{array}{l}\text { Pitch } \varnothing 8 \\
\mathrm{~mm}\end{array}$ & Cordierite & Spindle & $\begin{array}{l}200-1600 \\
\mathrm{rpm}\end{array}$ & $\begin{array}{l}\text { Tool } \\
\text { Radius }\end{array}$ & $12 \mathrm{~mm}$ \\
\hline
\end{tabular}

\section{Results and discussions}

\subsection{Experimental setup}

Experiments were implemented on a 7-axis CNC machine (IRP50, Zeeko), and the schematics of the platform is shown in Fig. 4(a) [26]. The ceramics shown in Fig. 4(b) were clamped on the XYZ axes of the machine, while the compliant tool was spinning on the $\mathrm{H}$ spindle. The automatic adjustment of attack angle was realized by the $\mathrm{A}$ axis. The photographs of the elastic tools listed in Table 2 corresponding to three compliant abrasive methods described in section 2.1 are shown in Fig. 4(c). 

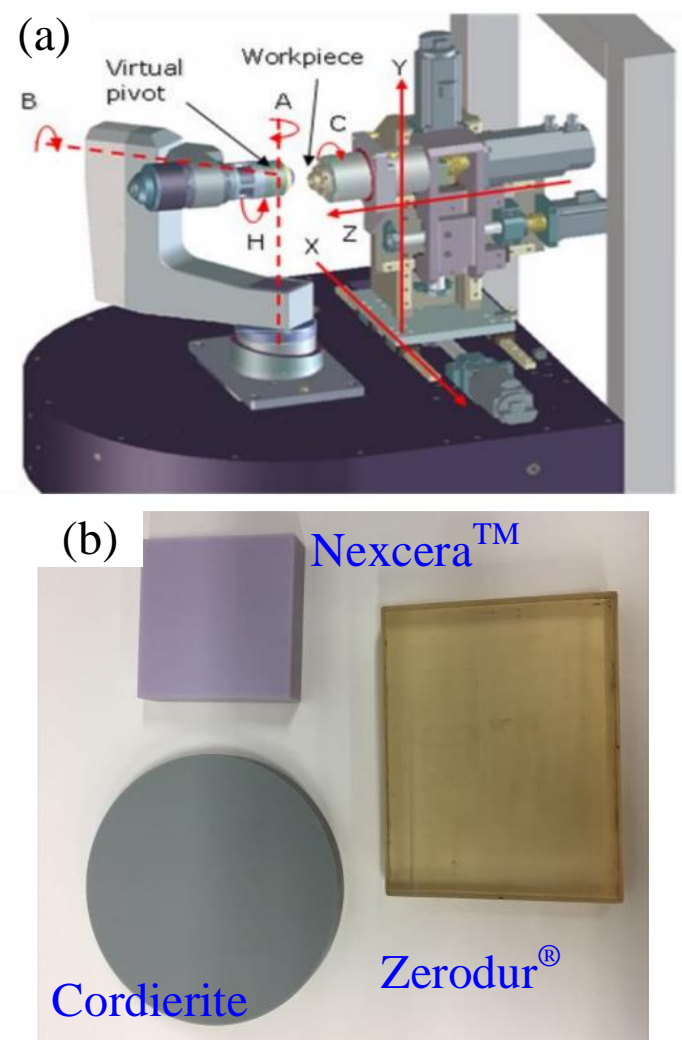
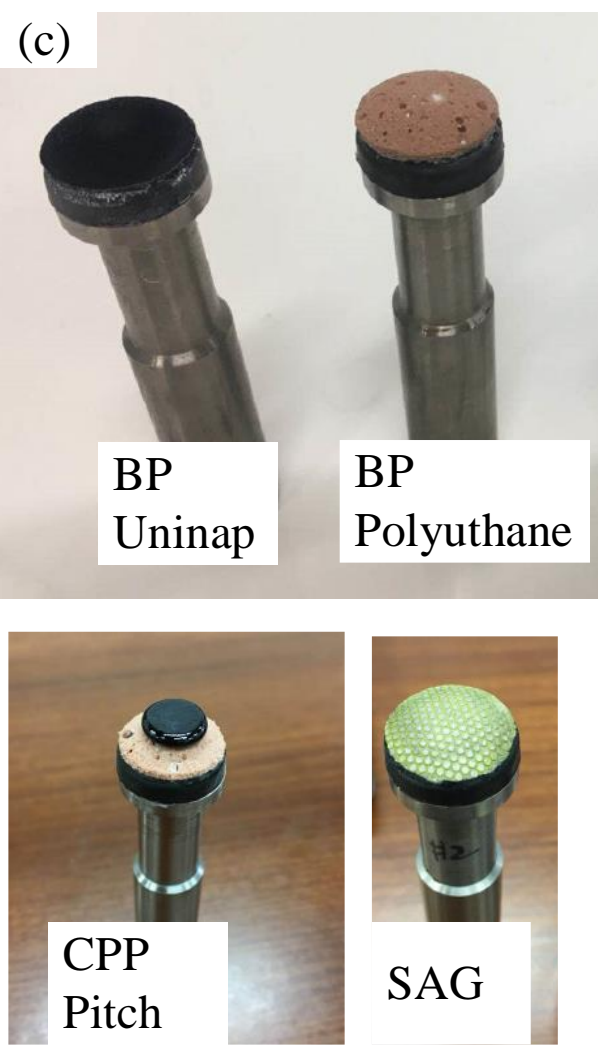

Fig. 4 (a) 7-axis CNC platform ${ }^{[26]}$, (b) photographs of three ceramics, (c) photographs of adopted compliant tools

\subsection{Processing of Nexcera ${ }^{T M}$ with different technologies}

Firstly, the process investigations on Nexcera $^{\mathrm{TM}}$ were conducted to have a basic understanding of material removal behavior under various technologies and conditions. Before executing the processing programs, the initial surface form and roughness values were measured. To guarantee the consistent evaluation, very smooth ceramics were specially prepared by fine diamond lapping, and the initial surface roughness was characterized to be $0.53 \mathrm{~nm}$ Ra with standard deviation of $0.09 \mathrm{~nm}$.

The elastic tools with different pad materials were applied in the bonnet polishing (BP) process by following the raster path illustrated in Fig. 2(a). According to 2.2, the evaluated removal form based on the tool with pad material of polyurethane is shown in Fig. 5(a). It can be seen that maximum removal depth occurs at the right corner of the map, corresponding to 
the largest offset of $0.4 \mathrm{~mm}$ and maximum attack angle of $30^{\circ}$. This is because large offset contributes to high pressure in the contact region, driving the grits to remove more materials. The large attack angle means high speed of each grit, resulting in high removal amount per unit time. The corresponding surface roughness at the diagonal positions is shown in Fig. 6. It can be observed that, with the increase in offset and attack angle, the surface roughness is remarkably increased from $0.57 \mathrm{~nm}$ to $8.37 \mathrm{~nm}$, indicating that the surface quality is sacrificed while improving the material removal rate (MRR).
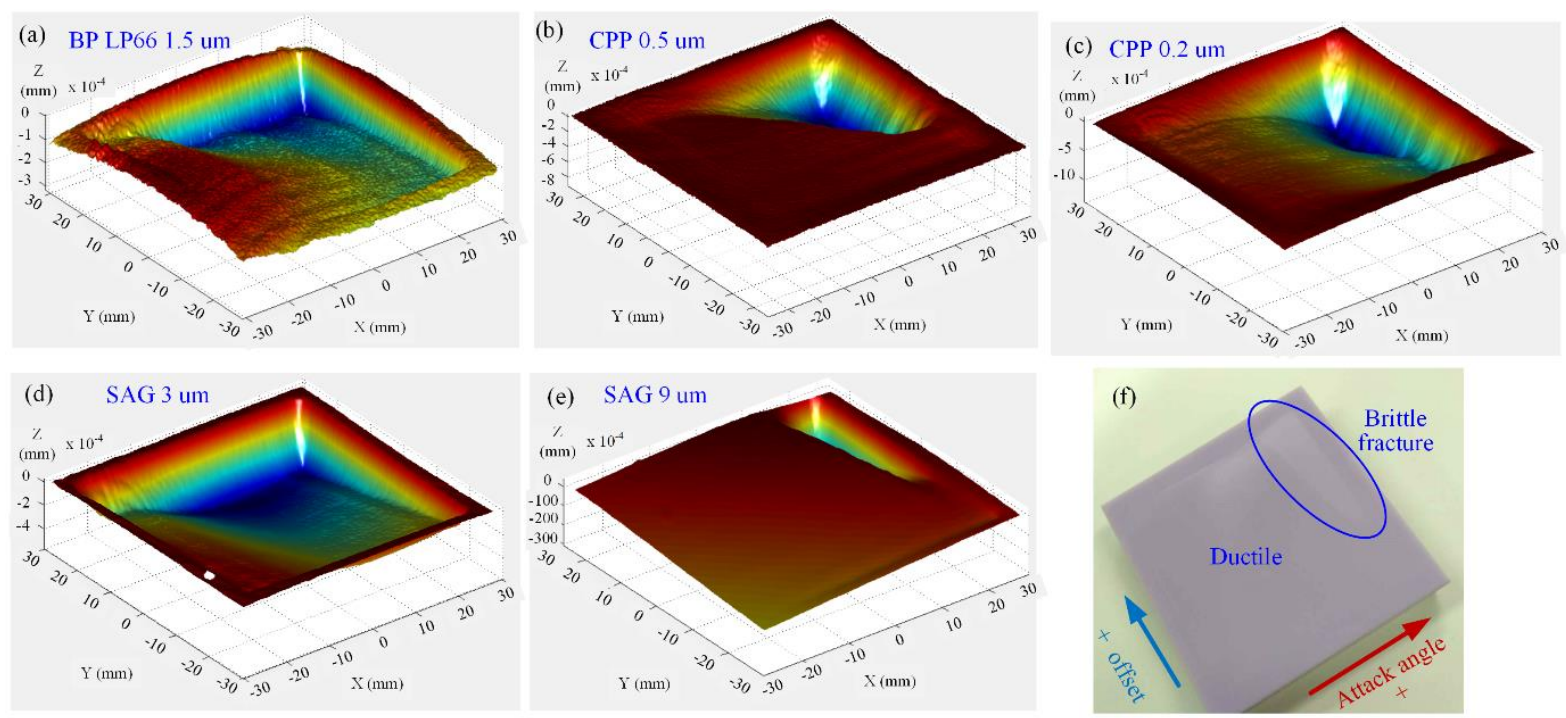

Fig. 5 Material removal profile after (a) bonnet polishing by polyurethane tool with $\mathrm{CeO}_{2}$ in $1.5 \mu \mathrm{m}$ grit size, (b) compliant pitch polishing with $\mathrm{CeO}_{2}$ in $0.5 \mu \mathrm{m}$ grit size, (c) compliant pitch polishing with $\mathrm{Al}_{2} \mathrm{O}_{3}$ in $0.2 \mu \mathrm{m}$ grit size, (d) shape adaptive grinding with $3 \mu \mathrm{m}$ grain, (e) shape adaptive grinding with $9 \mu \mathrm{m}$ grain, (f) photographs showing ductile and brittle modes

With the same rubber tool covered by softer uninap pad, the actual pressure induced by the pad asperity is much smaller, the removal depth becomes so low ( $\sim 20 \mathrm{~nm}$ in peak-valley) that the entire removal form cannot be distinguished well. Such low material removal rate makes it rather difficult to realize corrective polishing [14]. However, the surface quality can be improved compared with the case using polyurethane tool with the same grit size. The quantified MRR and surface roughness for the two conditions based on bonnet polishing are compared by the curves in Fig. 7. 


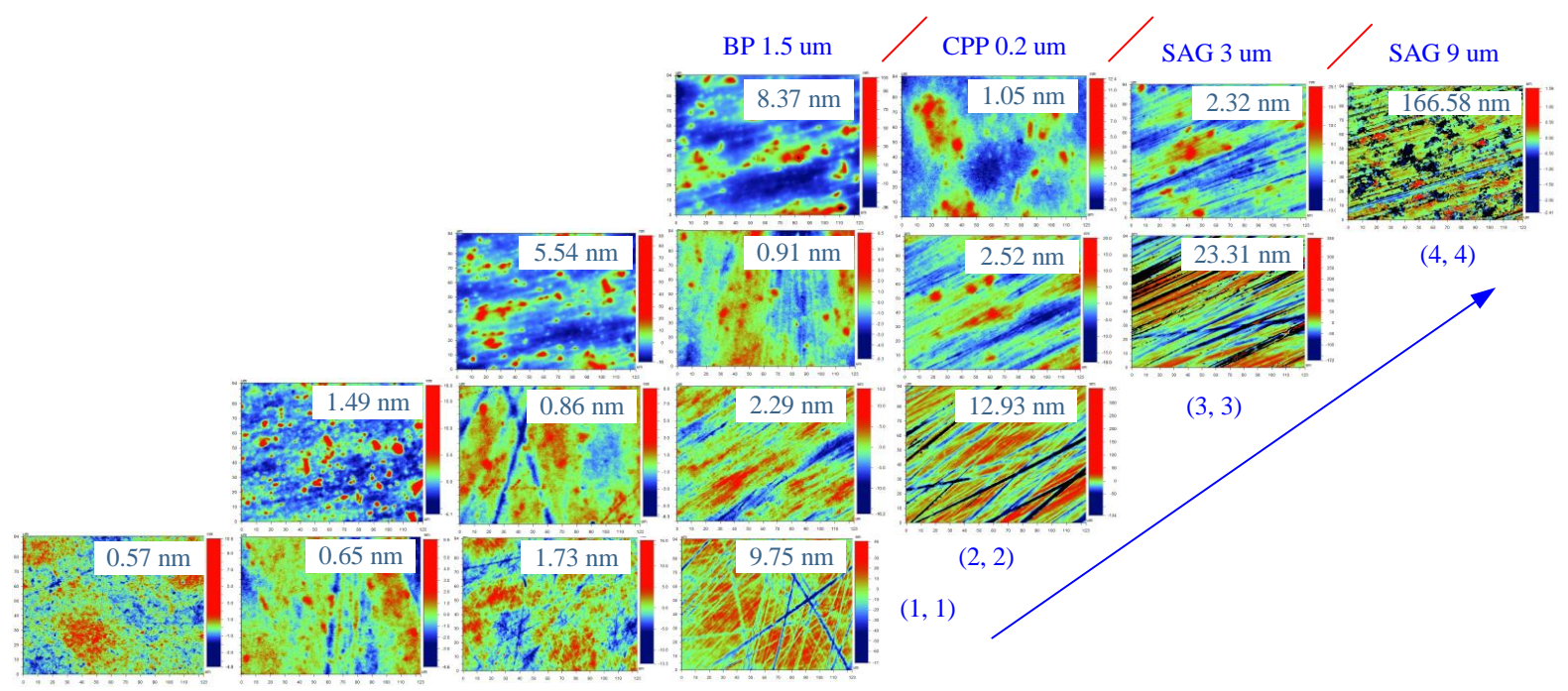

Fig. 6 Surface roughness after bonnet polishing by polyurethane tool with $\mathrm{CeO}_{2}$ in $1.5 \mu \mathrm{m}$ grit size, compliant pitch polishing with $\mathrm{Al}_{2} \mathrm{O}_{3}$ in $0.2 \mu \mathrm{m}$ grit size, shape adaptive grinding with $3 \mu \mathrm{m}$ grain and $9 \mu \mathrm{m}$ grain

With the same $1.5 \mu \mathrm{m}$ grit size slurry, by using the compliant pitch polishing (CPP) with pitch diameter of $8 \mathrm{~mm}$, the corresponding MRR is found to be much larger by evaluating the grid points at same diagonal positions. Meanwhile, the surface roughness value has been considerably decreased with less deviation, as shown in Fig. 7(b). It indicates that better surface quality can be obtained by the CPP method, as compared to BP method under the same conditions. By using smaller size grit $(0.5 \mu \mathrm{m})$, apparently the surface quality could be further improved, as the surface roughness value indicated in Fig. 7(b). Interestingly, the MRR was also improved as compared with using $1.5 \mu \mathrm{m}$ grit size. This is because, with the same concentration of $40 \mathrm{~g} / \mathrm{L}$, a larger amount of grits in small size would be involved in the material removal process. By using $\mathrm{Al}_{2} \mathrm{O}_{3}$ slurry $(0.2 \mu \mathrm{m}$ grit size $)$, as the trend of Fig. 7 indicates, the MRR was further increased with decreased surface roughness. The corresponding removal forms with $0.5 \mu \mathrm{m}$ and $0.2 \mu \mathrm{m}$ grits are shown in Fig. 5(b) \& (c), respectively.

To confirm the smooth finishing capability of presented shape adaptive grinding (SAG) method in ceramic processing, SAG tool bonded with average diamond size of $3 \mu \mathrm{m}$ shown 
in Fig. 4(c), was applied by keeping other machining variables the same as in BP process. The removal form is drawn in Fig. 5(d), and quantified on the curve of Fig. 7(a). By evaluating the surface roughness, it is found that smooth surface with average $2.2 \mathrm{~nm}$ in Ra can be obtained, which is even better than the BP process with finer grit size of $1.5 \mu \mathrm{m}$. This is particularly true when the large offset and attack angle (corresponding to $(3,3),(4,4)$ in Fig. 7(b)) is applied to remove large amount of materials. The results confirm that the machinability of Nexcera ${ }^{\mathrm{TM}}$ using SAG tool is even better than the BP tool. Nevertheless, with larger diamond size of $9 \mu \mathrm{m}$ in SAG process, the situation becomes different. As shown in the surface image of Fig. 6, scratching and grinding marks are obviously seen. Besides, at the $(4,4)$ position where largest offset is applied, brittle fracture is generated, thus leading to seriously degraded surface quality even though the high MRR is obtained.

Based on above analysis and especially the results in Fig. 7, SAG $9 \mu \mathrm{m}$ or larger grit size tool should be carefully used unless in very rough stage to remove extremely large amount of materials. Compared with BP which is normally considered as the final finishing process, SAG $3 \mu \mathrm{m}$ is recommended in higher priority, due to the improved MRR and surface quality as well as the fact that a slurry supply system is not necessary. It can be expected that better performance could be possibly achieved if SAG tool with finer diamond grain size could be manufactured in industry. For CPP process, surface roughness below $1 \mathrm{~nm}$ could be steadily achieved by adopting extremely fine grit size, and another advantage is the higher MRR can be obtained by forming larger size pitch on the elastic tool, as shown in Fig. 1(c). 

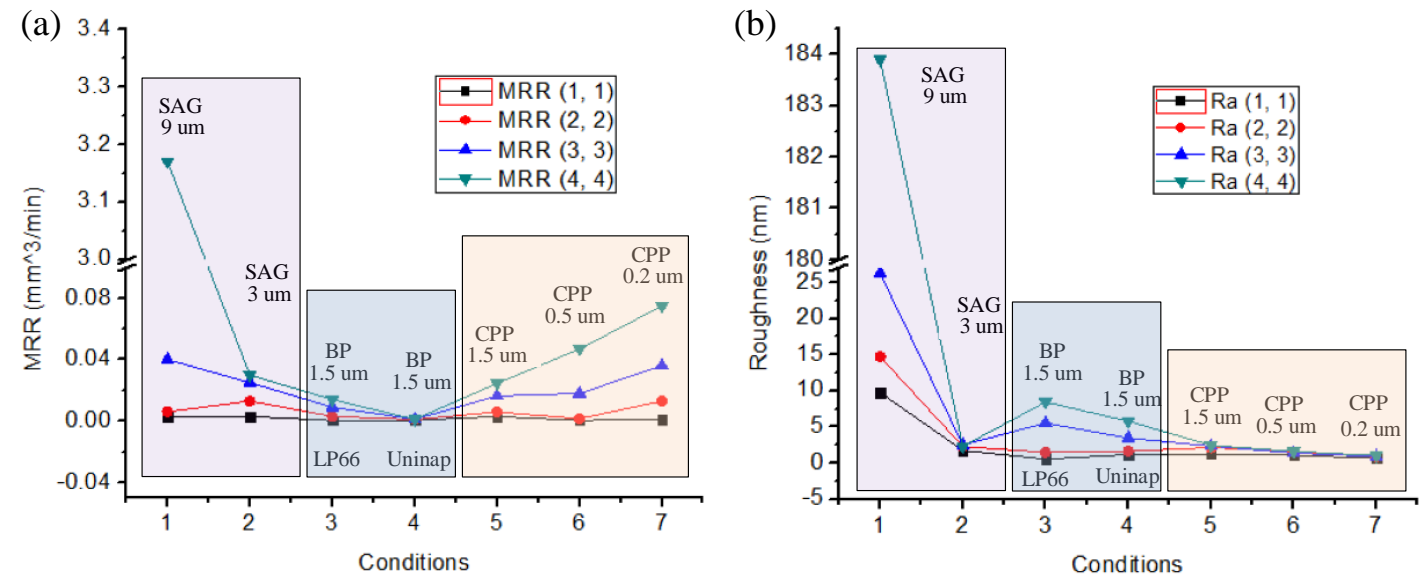

Fig. 7 Comparisons of (a) material removal rates and (b) surface roughness under different conditions

\subsection{Comparisons with Zerodur ${ }^{\circledR}$ and Cordierite}

Through above process investigations, the following advantageous conditions in ceramic processing are selected, implemented and compared with two low thermal expansion ceramics that are of great interest in industry.

\subsubsection{BP process}

Firstly, the above BP process with $1.5 \mu \mathrm{m} \mathrm{CeO}_{2}$ was applied to process three types of ceramics. Based on the machining parameters listed in Table 2, the processed ceramics were evaluated in the same way described in section 2.2 , the $3 \mathrm{D}$ histograms corresponding to $4 \times 4$ testing points, in terms of MRR and surface roughness, were obtained. A clear 3D trend can be seen from Fig. 8 is that the surface roughness is increasing with the increase in offset and attack angle for Nexcera ${ }^{\mathrm{TM}}$ and Cordierite. However, the machined surface roughness of Zerodur $^{\circledR}$ is not sensitive to the change in these two variables, and keeps a stable lowest value, as shown in Fig. 9(a) at diagonal positions. Meanwhile, the highest material removal rate can be achieved according to both Fig. 8 and Fig. 9(b). Compared with Cordierite, better surface roughness can be obtained for Nexcera ${ }^{\mathrm{TM}}$, with reduced MRR. 

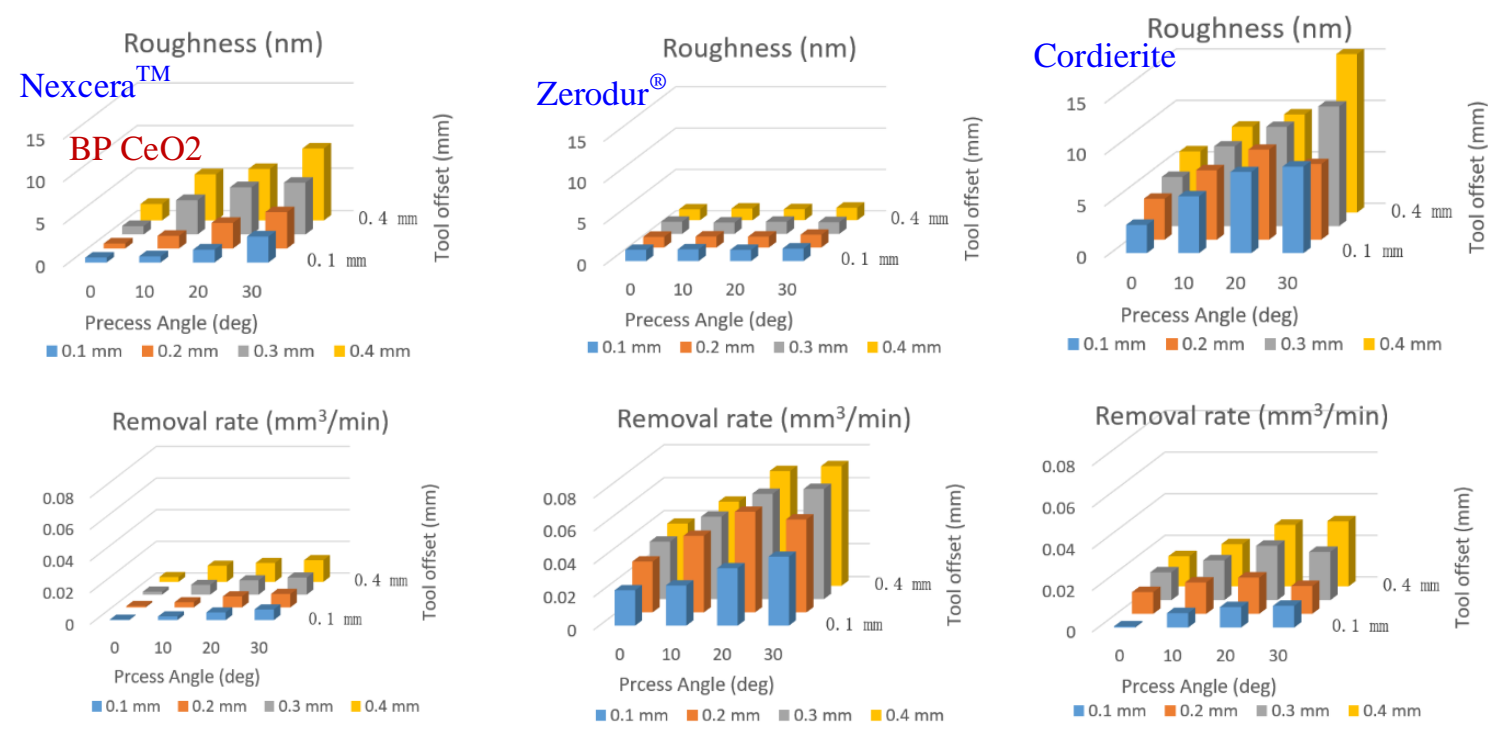

Fig. 8 Comparisons of material removal rate and surface roughness for different ceramics based on BP process
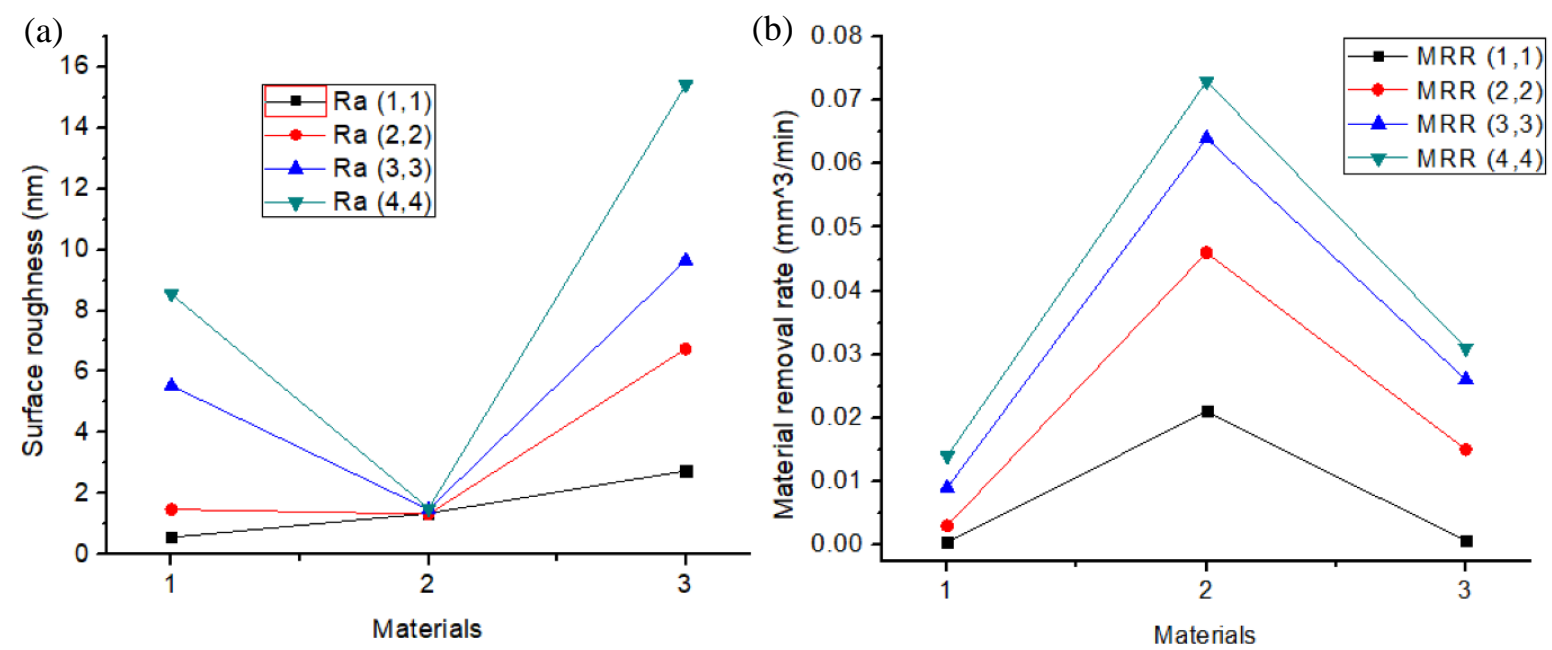

Fig. 9 (a) Surface roughness, and (b) material removal rate at different positions for three types of ceramics based on BP process (The Nexcera ${ }^{\mathrm{TM}}$, Zerodur $^{\circledR}$ and Cordierite are numbered as 1, 2 and 3, which is also applied to the subsequent figures)

The above phenomenon could be well explained by the following analysis which correlated material properties of the ceramics. For the polishing process, it can be assumed that material is removed when the substrate reaches yield stress under the action of the polishing grits with spherical shape. According to the plasticity model in polishing process, under the same condition, material removal rate satisfies:

$$
\mathrm{MRR} \sim R_{g}^{1 / 2}\left(\frac{F_{g}}{\sigma_{y} \cdot R_{g}}\right)^{2 / 3}
$$


where $R_{g}$ is the grit radius, $F_{g}$ is the applied force on the grit. $\sigma_{y}$ is the yield stress that can be estimated by one third of Vickers hardness $H_{v}$ [27]. Apparently from Table 1, the hardness of Zerodur ${ }^{\circledR}$ is much lower than the other two ceramics, indicating a higher MRR can be obtained based on Eq. (2). It agrees with the result in Fig. 9(b), where the highest MRR was achieved on Zerodur ${ }^{\circledR}$.

On the other hand, it is pointed out by Tabor that, when the average interaction pressure between the grit and workpiece is below 0.4 times hardness, the grit is rubbing on the workpiece without effective material removal [28]. Instead, it suffers from burnishing and friction, and some deformed material on the workpiece will recover, producing the material swelling with the increase in height [29]. Accordingly, this effect tends to occur on the ceramics with high hardness, leading to the degraded surface roughness. This can well explain why the surface roughness values are higher for Nexcera $^{\mathrm{TM}}$ and Cordierite in Fig. 9(a). On the contrary, this phenomenon does not dominate the Zerodur ${ }^{\circledR}$ material with much lower hardness, and thus the surface roughness is less affected by the process.

\subsubsection{CPP process}

As the best condition investigated in CPP process, $\mathrm{Al}_{2} \mathrm{O}_{3}$ grit in size of $0.2 \mu \mathrm{m}$ was adopted to study the difference in processing the three ceramic materials. In the same scale as in Fig. 9, Figure 10 indicates that much better surface qualities were achieved compared with the BP process, and that no clear tendency was observed for three kinds of materials. By comparison, the worst surface quality with close to $2 \mathrm{~nm}$ in $\mathrm{Ra}$ is generated for Cordierite. Nevertheless, better surfaces can be achieved for Nexcera ${ }^{\mathrm{TM}}$ and Zerodur ${ }^{\circledR}$, the average surface roughness of which are evaluated to be $0.87 \mathrm{~nm}$ and $1.07 \mathrm{~nm}$, respectively. As for MRR, by comparing the values at diagonal positions, it is found that approximately the same 
amount was obtained for different ceramics as shown in Fig. 11, indicating the MRR for CPP process is not quite dependent on the specific ceramics.
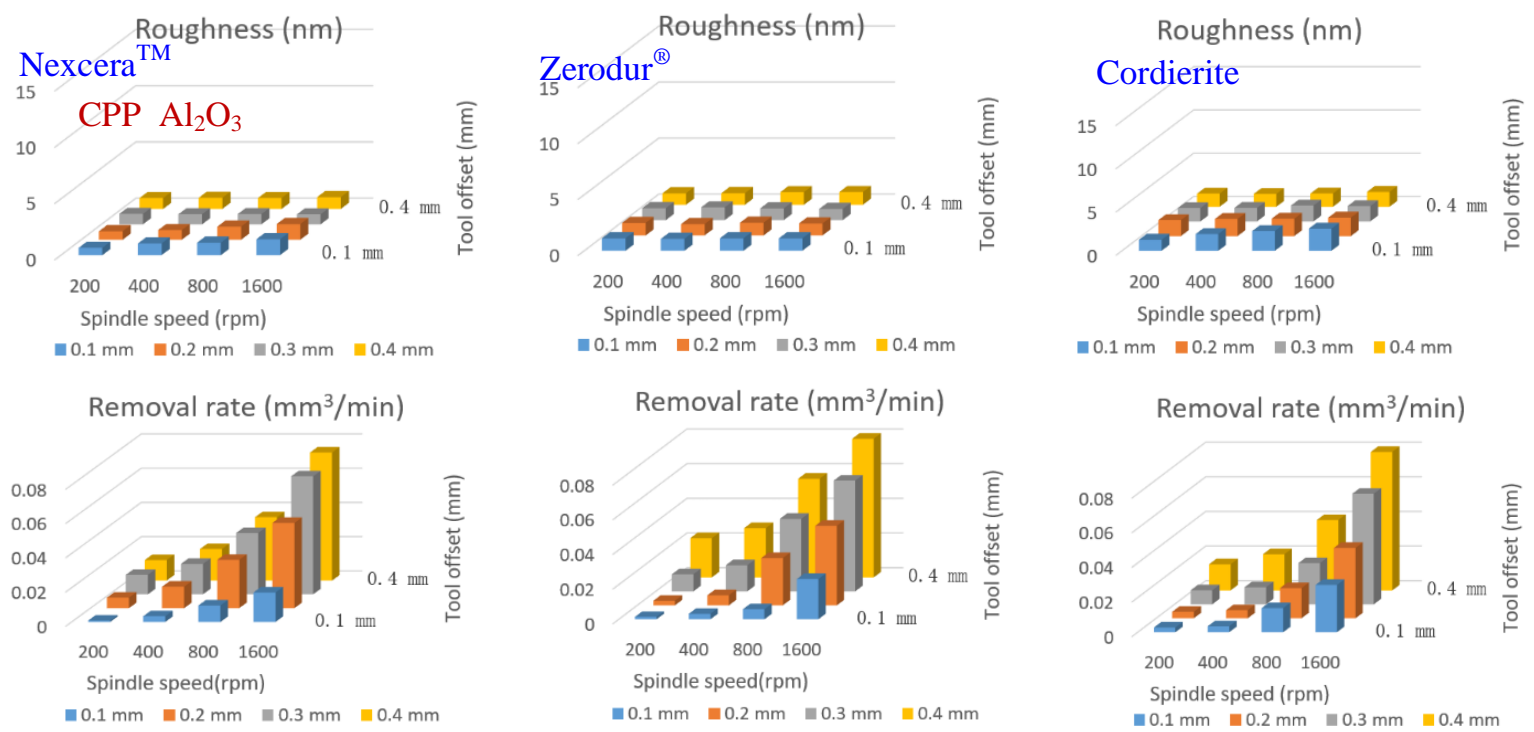

Fig. 10 Comparisons of material removal rate and surface roughness for different ceramics based on CPP process
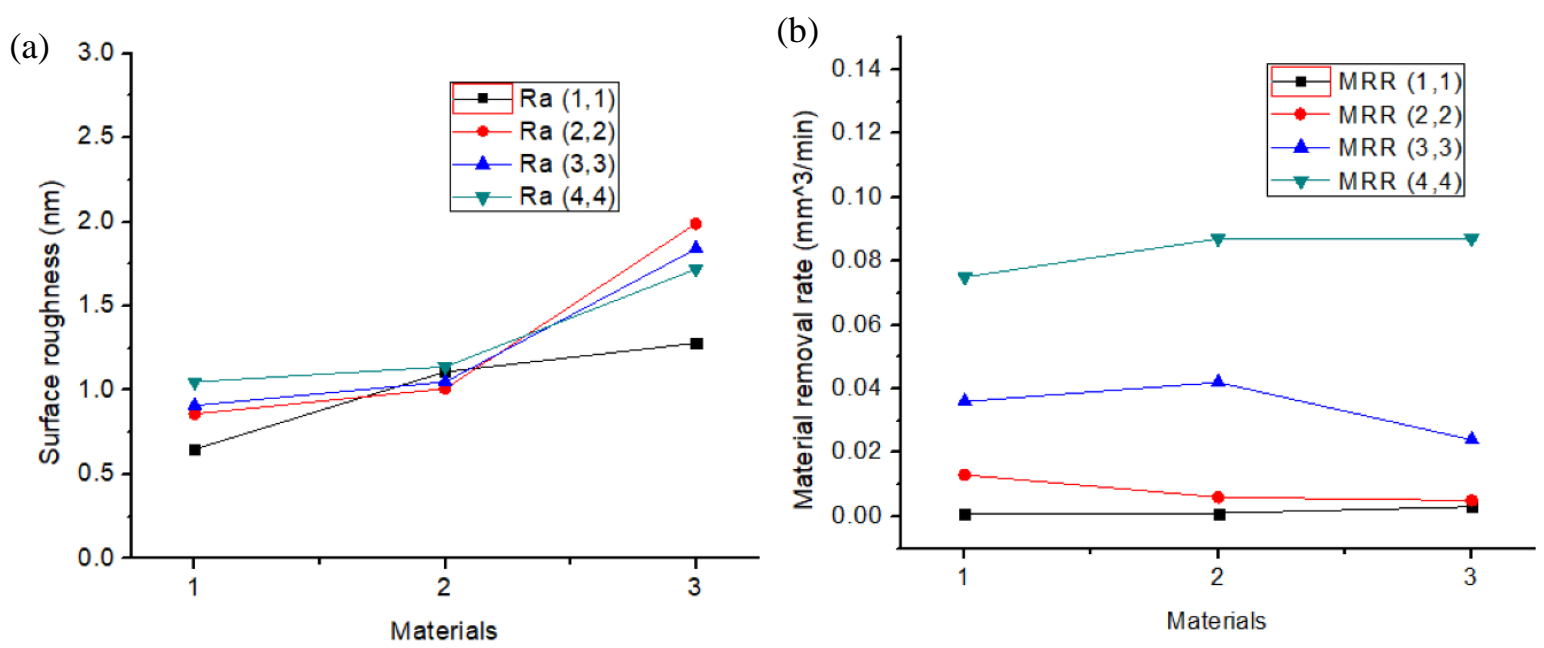

Fig. 11 (a) Surface roughness, and (b) material removal rate at different positions for three types of ceramics based on CPP process

With reference to [30], the workpiece and pitch are separated by the diameter of the slurry grits. It is considered that the penetration depth of the grit into the pitch is much larger for the workpiece with higher hardness. Based on the fact that the grits are not consistent size in reality, larger penetration depth into the pitch allows more grits, especially smaller ones, to be involved in the material removal process, making the number of active grits increase [31]. 
Due to this fact, even though the removal depth on harder material is smaller for each grit, the total removal volume does not drop, which can explain the results in Fig. 11(b) for three different ceramics with different hardness. However, considering that pitch is a very complex medium as stated in [30], more specific mechanism investigations should be conducted in future to clarify this matter.

\subsubsection{SAG process}
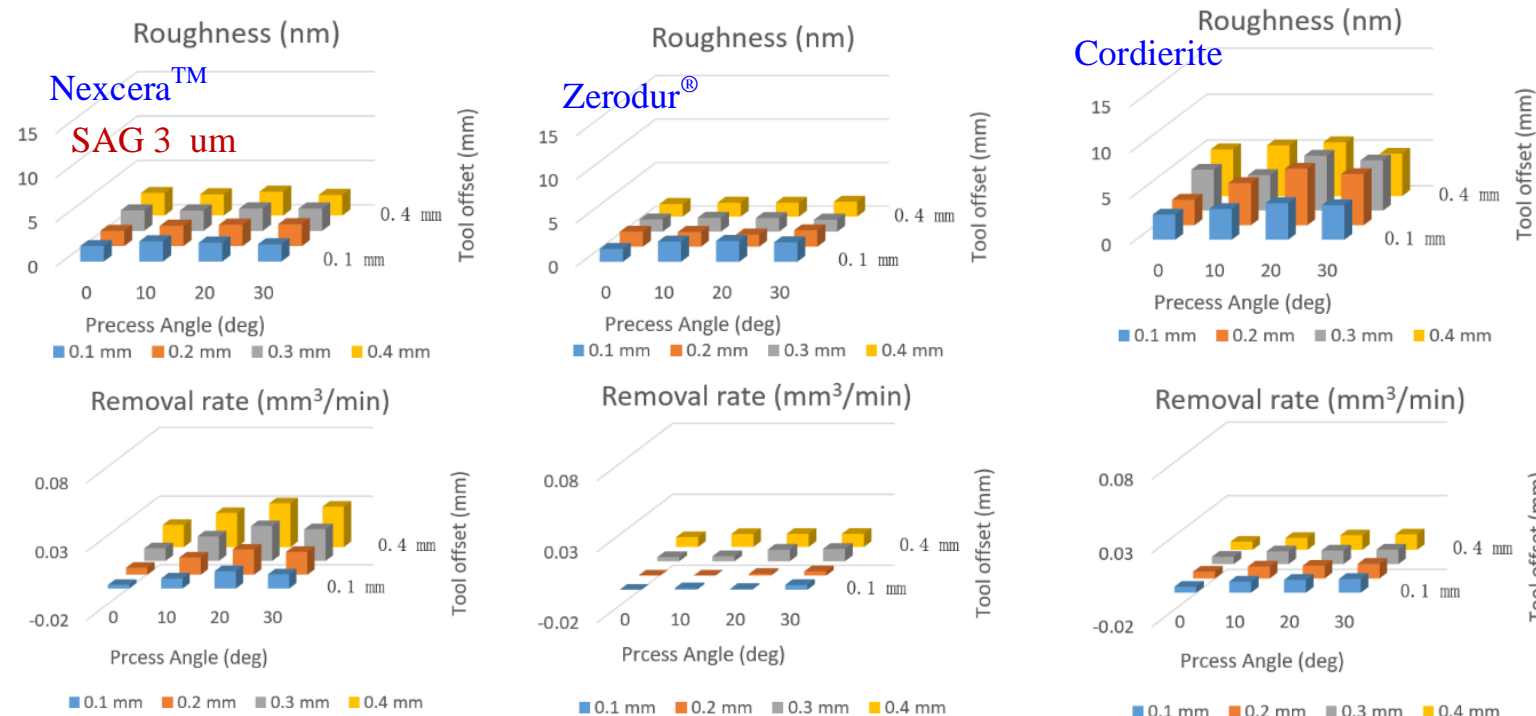

Removal rate $\left(\mathrm{mm}^{3} / \mathrm{min}\right)$

Removal rate $\left(\mathrm{mm}^{3} / \mathrm{min}\right)$
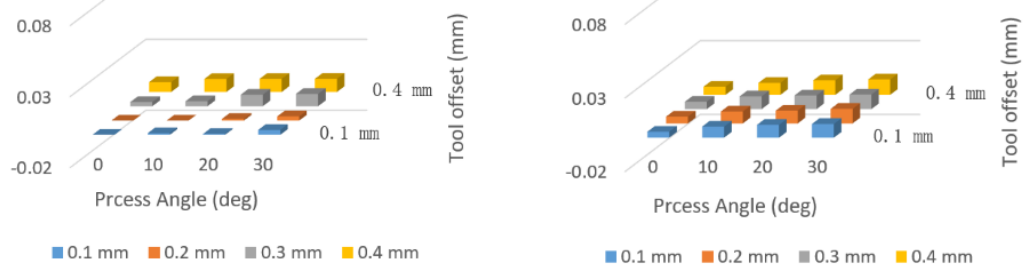

Fig. 12 Comparisons of material removal rate and surface roughness for different ceramics based on SAG process

Due to the smooth finishing capability of SAG $3 \mu \mathrm{m}$ in processing of Nexcera $^{\mathrm{TM}}$, it was also applied to the other two ceramics. From Fig. 12, regarding the MRR, it also displays an increasing tendency with the increase in offset and attack angle. For Zerodur ${ }^{\circledR}$ ceramic, optical surface with average roughness of $1.61 \mathrm{~nm}$ has been achieved as shown in Fig. 13(a). However, significantly lower MRR could be obtained for Zerodur ${ }^{\circledR}$, and approximately the same value for Cordierite, as quantified in Fig. 13(b). Moreover, the surface quality of processed Cordierite by SAG $3 \mu \mathrm{m}$ is much decreased than that of Nexcera ${ }^{\mathrm{TM}}$ and Zerodur ${ }^{\circledR}$. It can be concluded that while equally good average surface roughness around $2 \mathrm{~nm}$ can be obtained for both Zerodur $^{\circledR}$ and Nexcera ${ }^{\mathrm{TM}}$ ceramic, Nexcera ${ }^{\mathrm{TM}}$ offers much better MRR 
characteristics. The reason is considered to result from the highest fracture toughness value which makes the Nexcera ${ }^{\mathrm{TM}}$ exhibit better machinability in broader ductile region than Zerodur $^{\circledR}$, when the SAG process with fixed abrasives is applied.
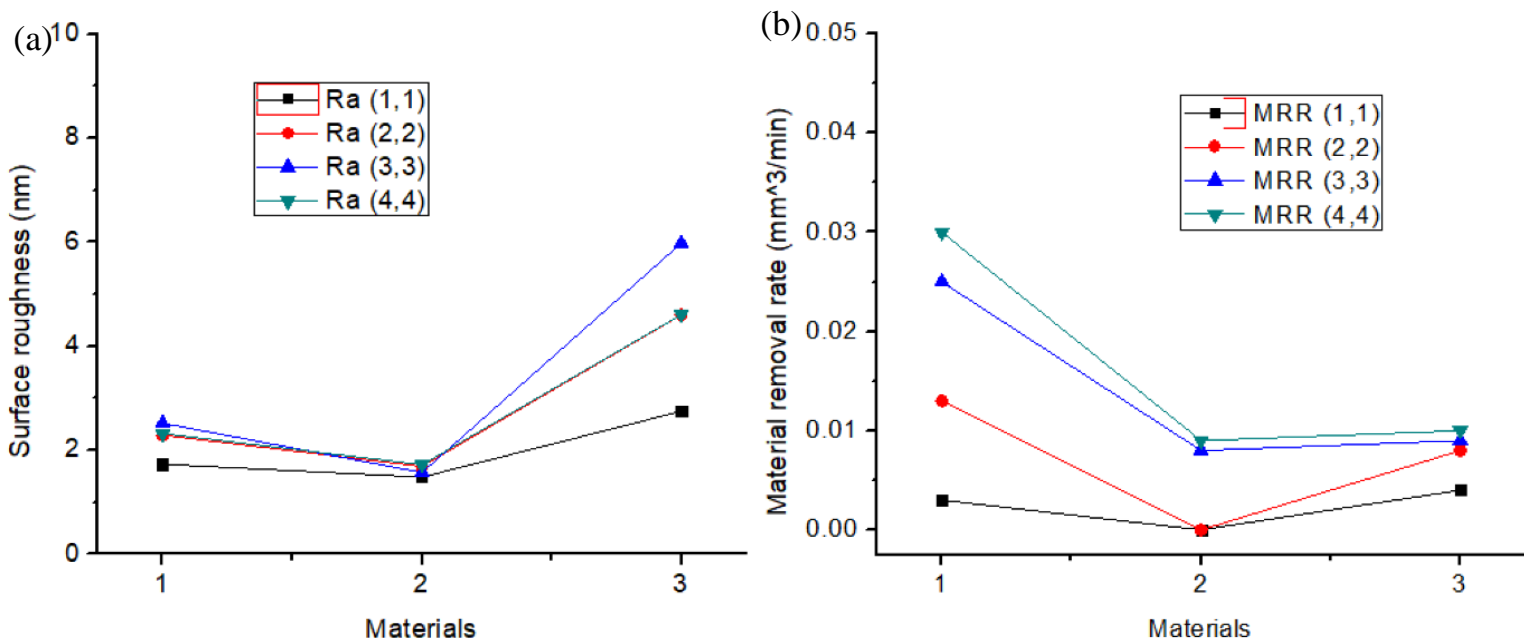

Fig. 13 (a) Surface roughness, and (b) material removal rate at different positions for three types of ceramics based on SAG process

In addition, it has been reported that the SAG $9 \mu \mathrm{m}$ tool generated an obvious ductile/fracture transition on the Nexcera ${ }^{\mathrm{TM}}$ as Fig. 5(f) shows. The same phenomenon occurs on the Zerodur ${ }^{\circledR}$ and Cordierite. For comparison, the surface roughness and MRR at positions $(2,2)$ and $(4,4)$ are typically evaluated and plotted in Fig. 14. It can be seen that, at $(4,4)$ position where extreme condition is applied, the surface roughness is remarkably increased up to more than $150 \mathrm{~nm}$ due to the brittle fracture with SAG $9 \mu \mathrm{m}$. On the contrary, ductile removal occurs at $(2,2)$ where the surface roughness is about $15 \mathrm{~nm}$. It is noted that the high roughness value is attributed to the scratches (ductile) from the large size grit, as the right side image in Fig. 6 show. Correspondingly, The MRR is also significantly higher at $(4,4)$ due to the lateral and radial crack propagations around the abrasive grits [32]. The same trend but far lower MRR is generated at ductile position (2, 2), as shown in Fig. 14(b). 

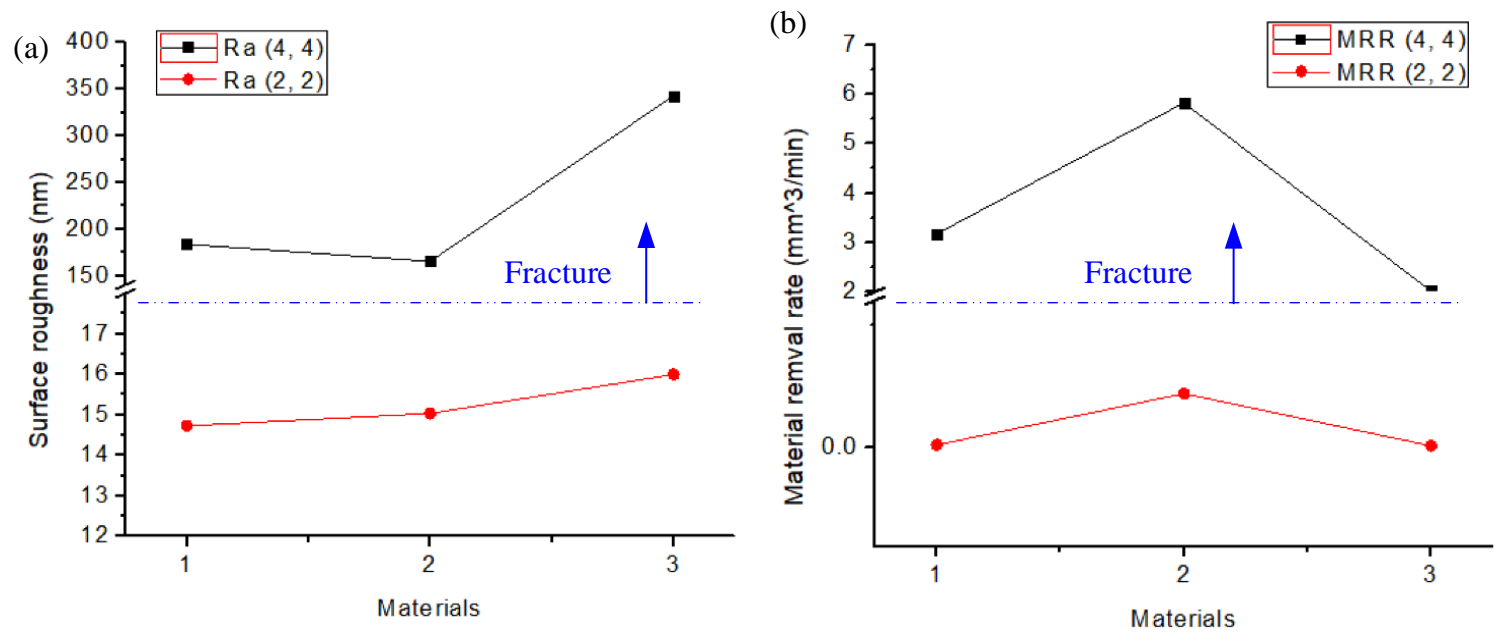

Fig. 14 (a) Surface roughness, and (b) material removal rate at different positions for three types of ceramics based on SAG process

For the ceramics materials, according to Bifano et al. [33], there is a critical penetration depth corresponding to the ductile-brittle transition, which is expressed by:

$$
d_{c}=\varphi\left(\frac{E}{H_{v}}\right)\left(\frac{K_{I C}}{H_{v}}\right)^{2}
$$

where is $E$ and $K_{I C}$ are the Young's modulus and fracture toughness of ceramics, respectively. $\varphi$ is the coefficient, which can be chosen as 0.15 for a large number of ceramics [34].

By substituting the ceramics properties listed in Table 1, the critical transition values are identified to be $77 \mathrm{~nm}, 37 \mathrm{~nm}$ and $55 \mathrm{~nm}$ for Nexcera ${ }^{\mathrm{TM}}$, Zerodur ${ }^{\circledR}$ and Cordierite, respectively. Apparently, Zerodur ${ }^{\circledR}$ has the minimum transition value, indicating the fracture is much easier to be generated and propagated compared with the other two. The analysis coincides with the experimental results shown in Fig. 14(b), where the significantly higher MRR is obtained for Zerodur ${ }^{\circledR}$ material under the same process conditions.

\subsection{Comparison summary}

\subsubsection{MRR versus Roughness}

Finally, the statistical plots describing the relationship between the MRR and surface roughness were drawn, in order to have a further overall understanding of the processing 
capability as well as the dependence on material for three presented compliant abrasive technologies. Based on 16 groups of data obtained by each processing method, all the values were scattered in the MRR-Ra plot. As shown in Fig. 15(a) for Nexcera ${ }^{\mathrm{TM}}$, it is clear to see that different conditions have different working domains. For using SAG $9 \mu \mathrm{m}$, the ductile removal domain is classified at the right-bottom part of the figure, indicating that poor surface quality is obtained with not high MRR. Particularly, when the large offset is applied, transition to fracture easily occurs where extreme high MRR and roughness are generated, corresponding to the right-upper corner domain in the figure. Nevertheless, the situation by using SAG $3 \mu \mathrm{m}$ is significantly improved, the machinability domain of which is located between that of $\mathrm{CPP}$ and $\mathrm{BP}$ with polyurethane. It means that even better surface quality and higher MRR can be obtained by SAG $3 \mu \mathrm{m}$ than BP process with finer girt size of $1.5 \mu \mathrm{m}$. The vertical narrow domain corresponding to CPP process with $0.2 \mu \mathrm{m}$ reveals that stable and highly enhanced surface quality can be obtained, and the MRR can be improved simultaneously. This can be realized by increasing the pitch size on the elastic tool, as previously explained.

For the Zerodur ${ }^{\mathbb{B}}$ and Cordierite, the same conclusion can be applied for the cases using CPP $0.2 \mu \mathrm{m}$ and SAG $9 \mu \mathrm{m}$, as shown in Fig. 15(b) \& (c). However, as opposite to Nexcera ${ }^{\mathrm{TM}}$, the machinability of Zerodur ${ }^{\circledR}$ by BP $1.5 \mu \mathrm{m}$ is far better, and the domain is located quite close to that of CPP process. The clue of best performance based on BP process among three ceramics can be also found in Fig. 9. Accidently, for Cordierite, its domain by using SAG $3 \mu \mathrm{m}$ is contained inside that by BP $1.5 \mu \mathrm{m}$, indicating better surface quality can be obtained but without improving the MRR by using SAG $3 \mu \mathrm{m}$. From the experimental results, the grinding based SAG process with minimum $3 \mu \mathrm{m}$ grain size can achieve better 
surface quality than bonnet polishing process for Nexcera $^{\mathrm{TM}}$ and Zerodur ${ }^{\circledR}$, but not for Cordierite. It can be concluded that the SAG process is capable to realize smooth surface $(\mathrm{Ra}<3 \mathrm{~nm})$ for broader finishing applications. It is worth mentioning that, out of 3 processes, SAG is the easiest to use as it employs filtered water or water/oil as coolant, which makes it applicable to large industrial 3-axis/5-axis machining centers. Also, it is not prone to contamination in the way slurries are.

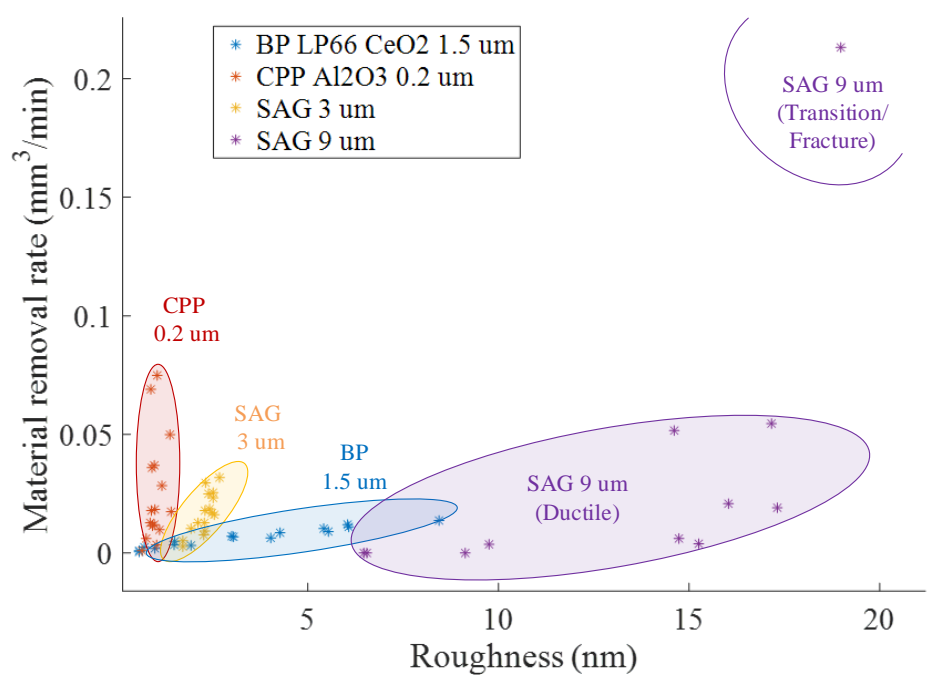

(a) Nexcera ${ }^{\mathrm{TM}}$

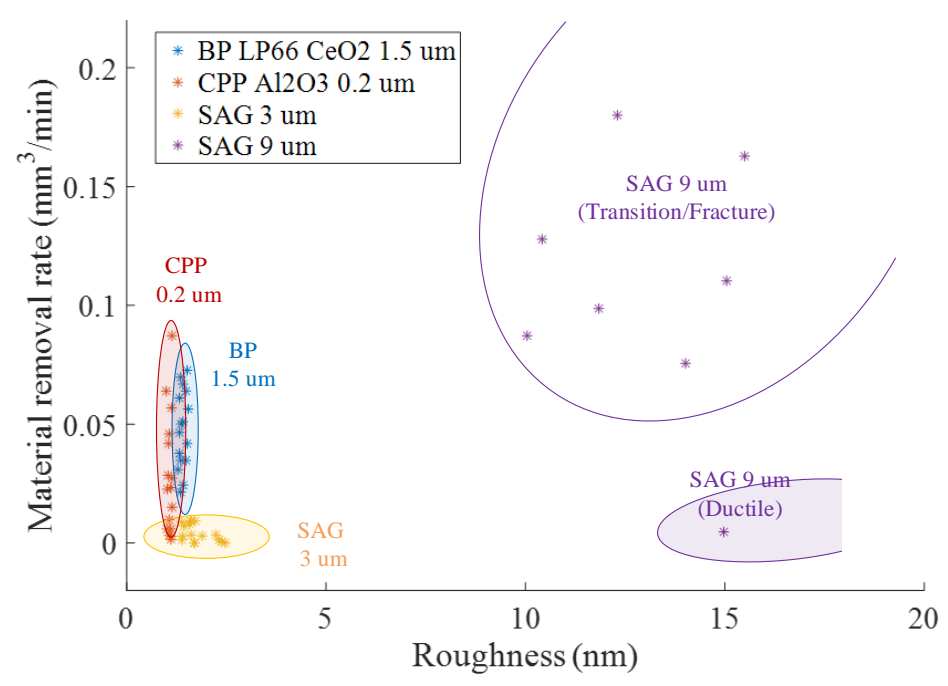

(b) Zerodur ${ }^{\circledR}$ 


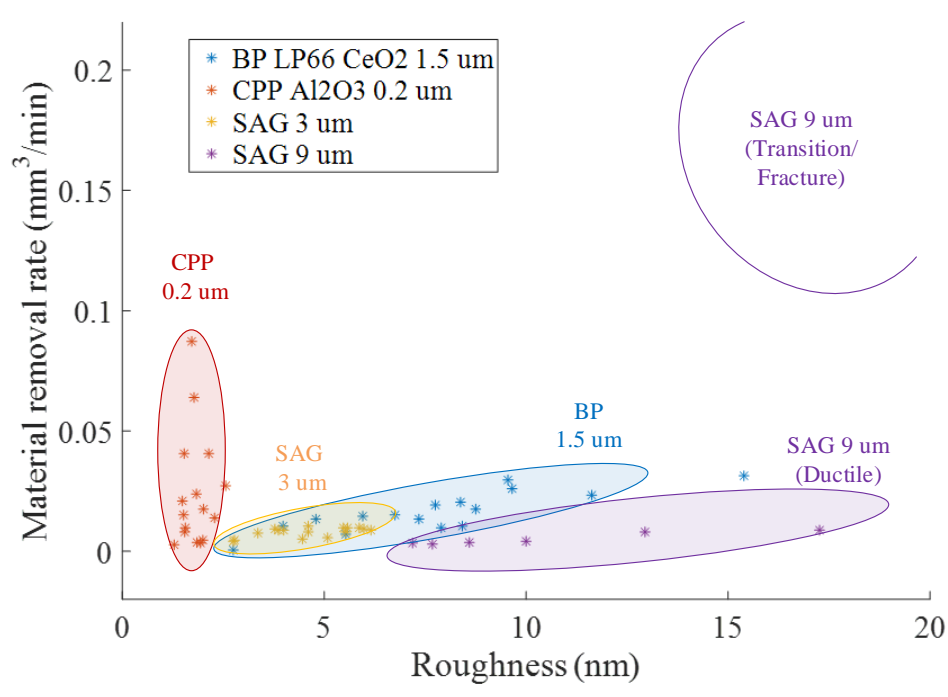

(c) Cordierite

Fig. 15 Processing domains using different compliant abrasive technologies

From Fig. 15, the compliant pitch polishing has the best machining performance for all three ceramics. As the stable and satisfactory surface roughness $(\operatorname{Ra}<2 \mathrm{~nm})$ can be achieved, it is recommended to be adopted in the final finishing process for only improving surface quality by using smaller pitch size, and with larger pitch size for corrective polishing. The disadvantage of CPP is that it cannot be well applied for the ceramics in freeform surface with large curvature variations, as the pitch cannot perfectly adapt to sudden surface variation in the contact region. The alternative methods are SAG with fine grit size and BP process, depending on the specific ceramics property according to this study.

\subsubsection{Microscopic observations and analysis}

To better understand the removal mechanism of the proposed compliant machining methods, microscopic observations were carried out on the surfaces processed by SAG and compliant finishing. Each image was obtained by high magnification (1000x) microscopy (VHX, Keyence), as shown in Fig. 16. 

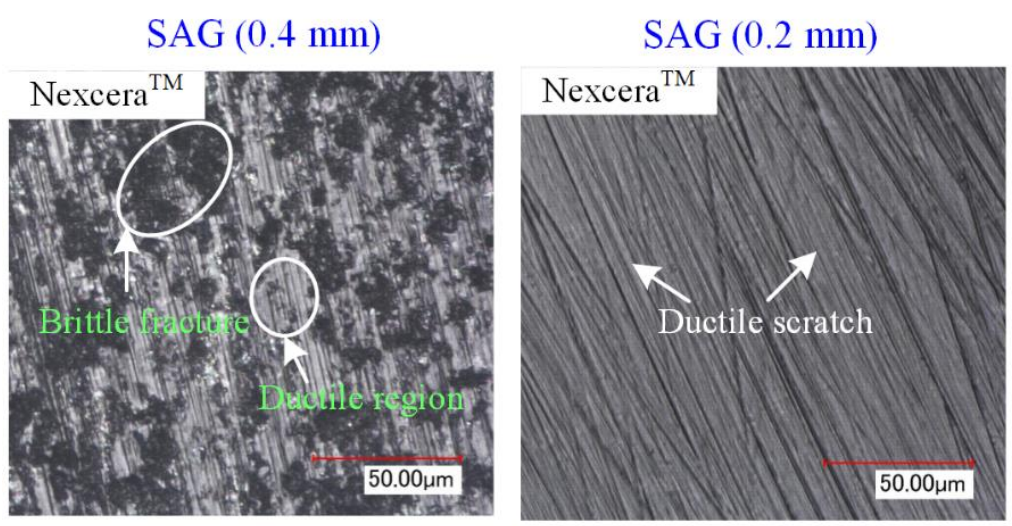

Pitch polishing $(0.2 \mathrm{~mm})$
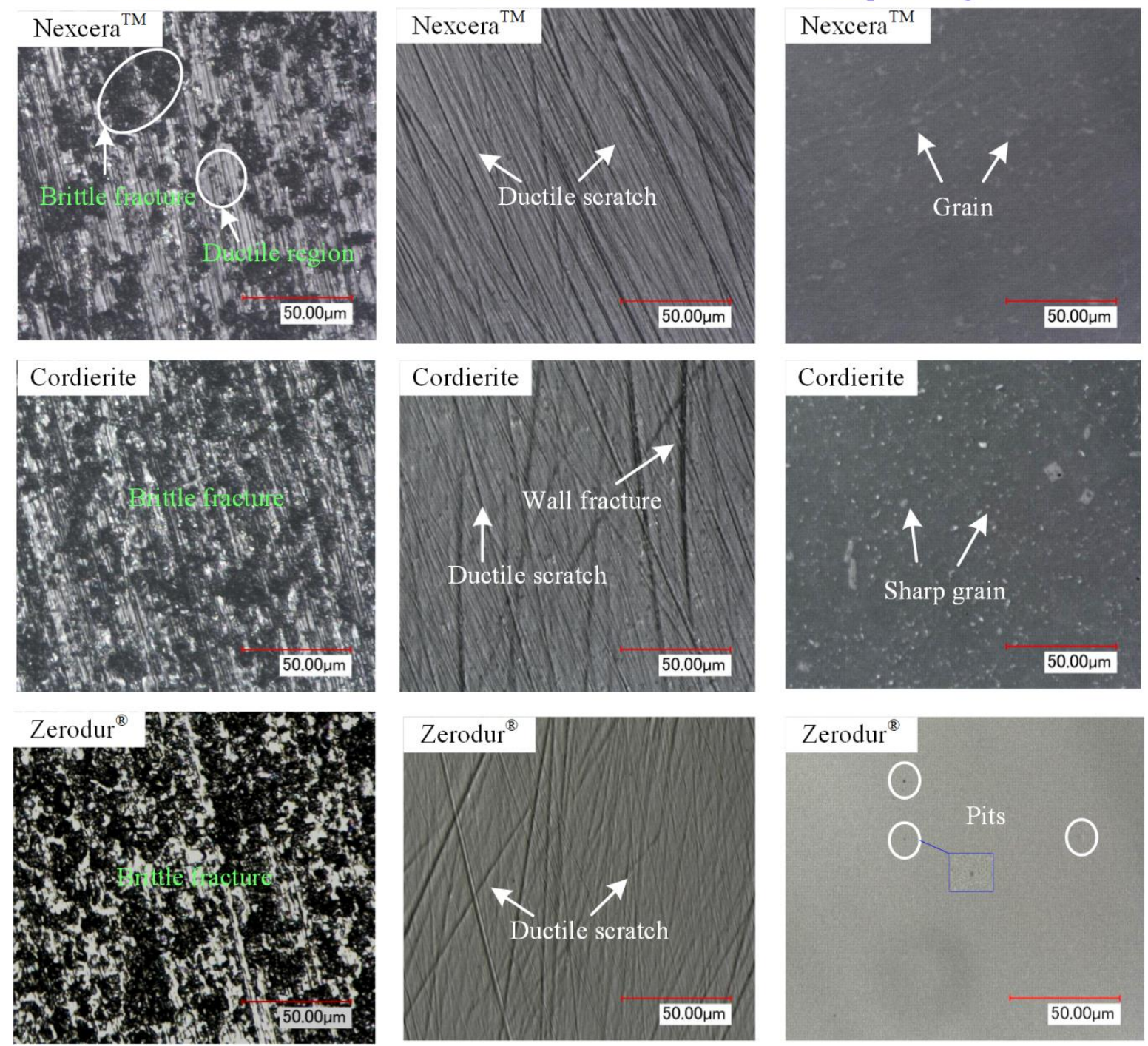

Fig. 16 Microscopic images of the three ceramics finished by different methods

The SAG process is able to achieve high removal rate but generates brittle fracture at a large offset $(0.4 \mathrm{~mm})$, as can be observed on all three ceramics. Nexcera ${ }^{\mathrm{TM}}$, as analyzed in section 3.3.3, exhibits better machinability with a broader ductile region than the other two ceramics. Thus, both fracture and ductile regions can be seen on the Nexcera ${ }^{\mathrm{TM}}$ surface, whereas fully fracture mode removal is seen on Cordierite and Zerodur ${ }^{\circledR}$ ceramics. At a smaller offset $(0.2 \mathrm{~mm})$, fully ductile mode is realized on Nexcera ${ }^{\mathrm{TM}}$ and Zerodur ${ }^{\circledR}$, whereas wall fracture with deep fractural scratches can be found on Cordierite ceramics. This explains 
the relatively higher roughness values of Cordierite in Fig. 13. Using compliant pitch polishing, very smooth surface can be obtained with no scratches. On the highly magnified 2D images in Fig. 16, grain tops are visible on Nexcera ${ }^{\mathrm{TM}}$ as anisotropic grain boundaries appear on the surface after polishing [35]. But the grains are smooth and do not protrude from the surface. By comparison, much clearer and sharper grains are observed on Cordierite, as on this specific ceramic material the grains elastically bury and bounce back behind the moving pitch tool [36]. For Zerodur ${ }^{\circledR}$ ceramics, a smooth surface with small pits was observed.

\subsubsection{X-ray diffraction analysis}

XRD analysis was employed to further evaluate the surface conditions shown in Fig. 16. The graph in Fig. 17 shows XRD diffraction patterns for the three ceramics. Similar patterns can be seen for Nexcera ${ }^{\mathrm{TM}}$ and Cordierite (PDF\#85-1722), while Zerodur ${ }^{\circledR}$ has a totally different material composition (PDF\#31-0707). Results for compliant pitch polishing, SAG ductile mode and SAG brittle mode are drawn in blue, red and orange colors, respectively. The maintained patterns seen on all three ceramics indicates that no phase transformation occurred under the different process approaches.

The pitch polished surfaces have the highest intensity (blue curve), particularly at the marked peaks $\left(2 \theta=10.4^{\circ}\right.$ for Nexcera ${ }^{\mathrm{TM}} /$ Cordierite, $^{2} \theta=25.7^{\circ}$ for Zerodur $\left.^{\circledR}\right)$. The figure also reveals that the intensity for Cordierite decreased after ductile mode machining by SAG, and reached lowest intensity after brittle mode machining by SAG. This is similar with processed silicon wafers, where high grinding force results in lower intensity of XRD pattern [25], as subsurface damage and crystal deformation with extra residual stress are generated. This 
seems to occur on Cordierite with the SAG process, which will lead to reduced mechanical strength [37]. By comparison, such decreasing trend in the XRD intensity is barely apparent for Nexcera ${ }^{\mathrm{TM}}$ and Zerodur $^{\circledR}$, from which we can assume that the SAG process does not generate obvious subsurface damage on these two specific ceramics.
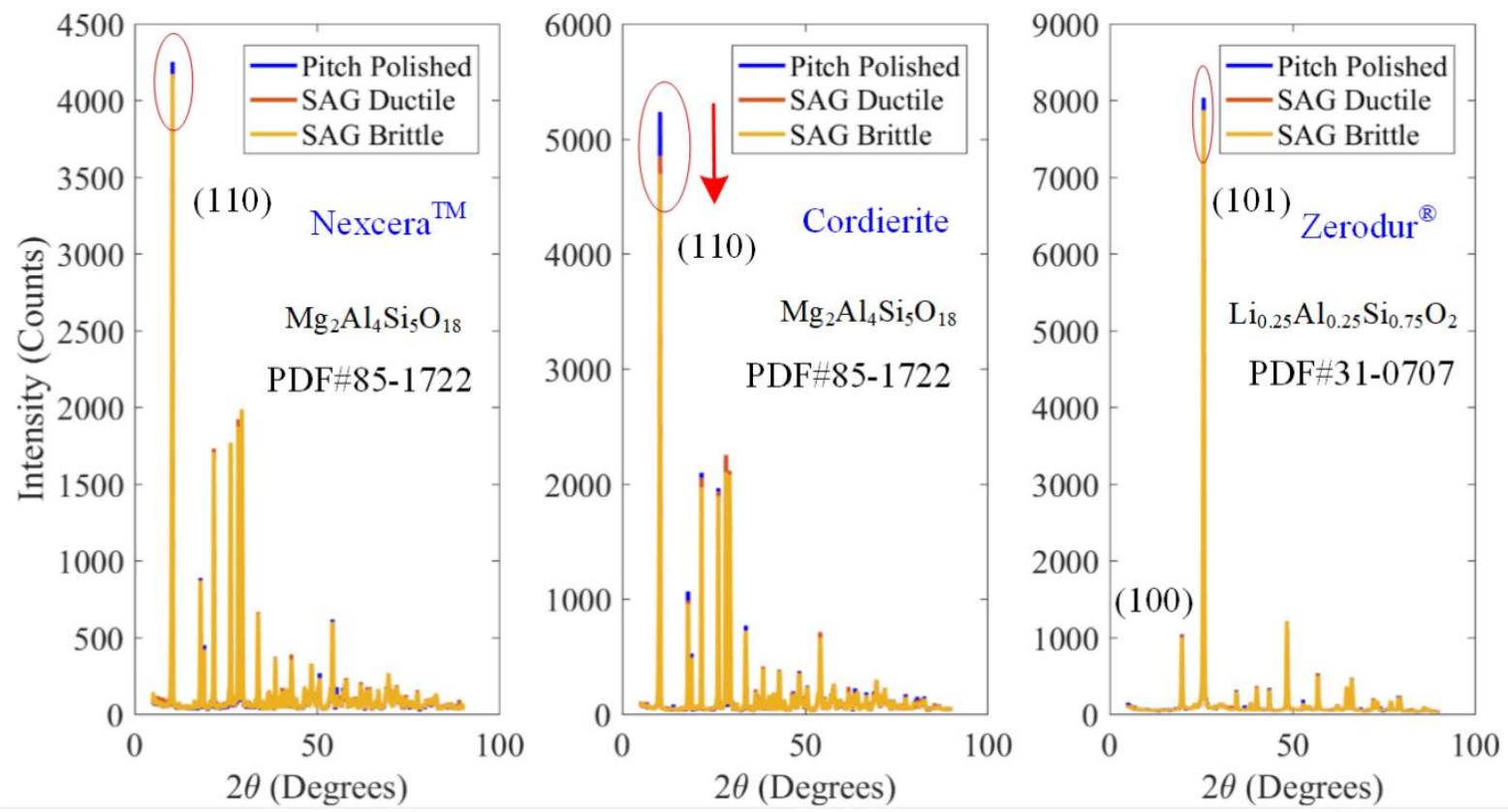

Fig. $17 \mathrm{X}$-ray diffraction patterns of three ceramics finished by different processes

\section{Conclusions}

This paper presents the experimental study on processing performances of low thermal expansion ceramics based on three compliant finishing technologies, namely bonnet polishing, compliant pitch polishing and shape adaptive grinding. The following important conclusions are drawn for providing future process guidance:

1) Consistently for all three ceramics, compliant pitch polishing can achieve the best optical surface quality $(<2 \mathrm{~nm})$ and meanwhile largest material removal rate $(\sim 0.08$ $\mathrm{mm}^{3} / \mathrm{min}$ ) in ductile mode, with increase in spindle speed and tool offset.

2) Bonnet polishing with $1.5 \mu \mathrm{m} \mathrm{CeO}_{2}$ is much more suitable for Zerodur ${ }^{\circledR}$ than other ceramics. The material removal rate can be largely improved by increasing the precess 
angle and offset, and interestingly stable surface roughness of about $2 \mathrm{~nm}$ can be achieved.

3) For Nexcera ${ }^{\mathrm{TM}}$, shape adaptive grinding with fine grain size of $3 \mu \mathrm{m}$ can realize better surface roughness and a higher material removal rate, as compared to bonnet polishing.

4) Better machinability is expected with finer grain size, but larger grain size clearly tends to initiate fracture, especially for Zerodur $^{\circledR}$ which has the lowest fracture toughness of the ceramics investigated.

5) X-ray diffraction analysis indicates that no phase transformation occurs on the ceramic surfaces finished by either compliant pitch or SAG in ductile and brittle mode. It also reveals that the SAG process does not generate much subsurface deformation on Nexcera ${ }^{\mathrm{TM}}$ and Zerodur $^{\circledR}$.

6) The processing ability between shape adaptive grinding with fine grain size and bonnet polishing depends on the material properties of specific ceramics, but the shape adaptive grinding is more promising and recommended in ceramic processing, especially if finer grain size tool can be manufactured.

\section{Acknowledgments}

This work was supported by the Grant-in-Aid for Scientific Research No. 17K14571 from the Japan Society for Promotion of Science, and the grant program for research and development from the Mazak foundation. The authors acknowledge support from Zeeko Ltd. in loaning the polishing equipment, and Krosaki Harima Co. for supporting this joint research program and providing ceramic samples. 


\section{References}

[1] M. Islam, A.S. Kumar, S. Balakumar, H. Lim, M. Rahman, Characterization of ELID grinding process for machining silicon wafers, Journal of materials processing technology, 198 (2008) 281-290.

[2] A.N. Samant, N.B. Dahotre, Laser machining of structural ceramics - a review, Journal of the European Ceramic Society, 29 (2009) 969-993.

[3] I.D. Marinescu, Handbook of advanced ceramics machining, CRC Press2006.

[4] A.W. Momber, R. Kovacevic, Principles of abrasive water jet machining, Springer Science \& Business Media2012.

[5] A. Schubert, H. Zeidler, M. Hahn, M. Hackert-Oschätzchen, J. Schneider, Micro-EDM milling of electrically nonconducting zirconia ceramics, Procedia CIRP, 6 (2013) 297-302.

[6] A.N. Samant, N.B. Dahotre, Computational predictions in single-dimensional laser machining of alumina, International Journal of Machine Tools and Manufacture, 48 (2008) 1345-1353.

[7] C.-H. Tsai, H.-W. Chen, Laser milling of cavity in ceramic substrate by fracture-machining element technique, Journal of materials processing technology, 136 (2003) 158-165.

[8] C.-W. Chang, C.-P. Kuo, Evaluation of surface roughness in laser-assisted machining of aluminum oxide ceramics with Taguchi method, International Journal of Machine Tools and Manufacture, 47 (2007) 141-147.

[9] K. Katahira, H. Ohmori, S. Takesue, J. Komotori, K. Yamazaki, Effect of atmospheric-pressure plasma jet on polycrystalline diamond micro-milling of silicon carbide, CIRP Annals, 64 (2015) 129-132.

[10] W.-L. Zhu, Y. He, K.F. Ehmann, A.J.S. Egea, X. Wang, B.-F. Ju, Z. Zhu, Theoretical and experimental investigation on inclined ultrasonic elliptical vibration cutting of alumina ceramics, Journal of manufacturing science and engineering, 138 (2016) 121011.

[11] E. Shamoto, T. Moriwaki, Study on elliptical vibration cutting, CIRP Annals-Manufacturing Technology, 43 (1994) 35-38.

[12] G. Chryssolouris, N. Anifantis, S. Karagiannis, Laser assisted machining: an overview, Journal of manufacturing science and engineering, 119 (1997) 766-769.

[13] E. Uhlmann, G. Spur, Surface formation in creep feed grinding of advanced ceramics with and without ultrasonic assistance, CIRP Annals, 47 (1998) 249-252.

[14] A. Beaucamp, Y. Namba, I. Inasaki, H. Combrinck, R. Freeman, Finishing of optical moulds to $\lambda / 20$ by automated corrective polishing, CIRP Annals-Manufacturing Technology, 60 (2011) 375-378.

[15] Y. Zhao, L. Chang, A micro-contact and wear model for chemical-mechanical polishing of silicon wafers, Wear, 252 (2002) 220-226.

[16] W.I. Kordonski, S. Jacobs, Magnetorheological finishing, International Journal of modern physics B, 10 (1996) 2837-2848.

[17] M. Weiser, Ion beam figuring for lithography optics, Nuclear Instruments and Methods in Physics Research Section B: Beam Interactions with Materials and Atoms, 267 (2009) 1390-1393.

[18] H. Suzuki, S. Hamada, T. Okino, M. Kondo, Y. Yamagata, T. Higuchi, Ultraprecision finishing of micro-aspheric surface by ultrasonic two-axis vibration assisted polishing, CIRP Annals, 59 (2010) 347-350. 
[19] H. Ohmori, I. Takahashi, B. Bandyopadhyay, Ultra-precision grinding of structural ceramics by electrolytic in-process dressing (ELID) grinding, Journal of materials processing technology, 57 (1996) 272-277.

[20] D.D. Walker, A. Beaucamp, R.G. Bingham, D. Brooks, R. Freeman, S. Kim, A. King, G. McCavana, R. Morton, D. Riley, Precessions process for efficient production of aspheric optics for large telescopes and their instrumentation, Specialized Optical Developments in Astronomy, International Society for Optics and Photonics, 2003, pp. 73-85.

[21] A. Beaucamp, Y. Namba, P. Charlton, Corrective finishing of extreme ultraviolet photomask blanks by precessed bonnet polisher, Applied optics, 53 (2014) 3075-3080.

[22] A. Beaucamp, Y. Namba, H. Combrinck, P. Charlton, R. Freeman, Shape adaptive grinding of CVD silicon carbide, CIRP Annals-Manufacturing Technology, 63 (2014) 317-320.

[23] H. Luo, M. Guo, S. Yin, F. Chen, S. Huang, A. Lu, Y. Guo, An atomic-scale and high efficiency finishing method of zirconia ceramics by using magnetorheological finishing, Applied Surface Science, 444 (2018) 569-577.

[24] H. Luo, S. Yin, G. Zhang, C. Liu, Q. Tang, M. Guo, Optimized pre-thinning procedures of ion-beam thinning for TEM sample preparation by magnetorheological polishing, Ultramicroscopy, 181 (2017) 165-172.

[25] U. Bismayer, E. Brinksmeier, B. Güttler, H. Seibt, C. Menz, Measurement of subsurface damage in silicon wafers, Precision Engineering, 16 (1994) 139-144.

[26] A. Beaucamp, Y. Namba, Super-smooth finishing of diamond turned hard X-ray molding dies by combined fluid jet and bonnet polishing, CIRP Annals-Manufacturing Technology, 62 (2013) 315-318.

[27] D. Tabor, The hardness of metals, Clarendon, Oxford, 1951.

[28] Y. Zhao, D.M. Maietta, L. Chang, An asperity microcontact model incorporating the transition from elastic deformation to fully plastic flow, Journal of Tribology, 122 (2000) 86-93.

[29] C. He, W. Zong, T. Sun, Origins for the size effect of surface roughness in diamond turning, International Journal of Machine Tools and Manufacture, 106 (2016) 22-42.

[30] N. Brown, Optical polishing pitch, California Univ., Livermore (USA). Lawrence Livermore Lab., 1977.

[31] J. Luo, D.A. Dornfeld, Material removal mechanism in chemical mechanical polishing: theory and modeling, IEEE Transactions on Semiconductor Manufacturing, 14 (2001) $112-133$.

[32] B.R. Lawn, A. Evans, D. Marshall, Elastic/plastic indentation damage in ceramics: the median/radial crack system, Journal of the American Ceramic Society, 63 (1980) 574-581.

[33] T.G. Bifano, T.A. Dow, R.O. Scattergood, Ductile-regime grinding: a new technology for machining brittle materials, Journal of Engineering for Industry, 113 (1991) 184-189.

[34] A. Beaucamp, P. Simon, P. Charlton, C. King, A. Matsubara, K. Wegener, Brittle-ductile transition in shape adaptive grinding (SAG) of $\mathrm{SiC}$ aspheric optics, International Journal of Machine Tools and Manufacture, 115 (2017) 29-37.

[35] Y. Namba, H. Tsuwa, Surface properties of polished stainless steel, CIRP Annals-Manufacturing Technology, 29 (1980) 409-412.

[36] L.M. Cook, Chemical processes in glass polishing, Journal of non-crystalline solids, 120 (1990) 152-171. 
[37] W. Lu, Z. Pei, J. Sun, Non-destructive evaluation methods for subsurface damage in silicon wafers: a literature review, International Journal of Machining and Machinability of Materials, 2 (2007) 125-142. 